\title{
Did patients with COVID-19 receive timely treatment in the early epidemic? - a systematic review and meta-analysis
}

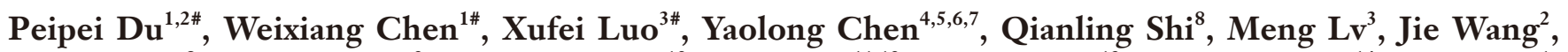 \\ Xuemei Shi ${ }^{9}$, Xiaofeng $\mathrm{Ma}^{2}$, Tianying Yang ${ }^{10}$, Shuya Lu ${ }^{11,12}$, Tingting $\mathrm{Li}^{13}$, Xiaokun Yang ${ }^{14}$, Shu Yang ${ }^{1}$, \\ Xixi Feng ${ }^{2}$; on behalf of COVID-19 Evidence and Recommendations Working Group
}

${ }^{1}$ College of Medical Information Engineering, Chengdu University of Traditional Chinese Medicine, Chengdu, China; ${ }^{2}$ School of Public Health, Chengdu Medical College, Chengdu, China; ${ }^{3}$ School of Public Health, Lanzhou University, Lanzhou, China; ${ }^{4}$ Evidence-Based Medicine Center, School of Basic Medical Sciences, Lanzhou University, Lanzhou, China; ${ }^{5}$ WHO Collaborating Centre for Guideline Implementation and Knowledge Translation, Lanzhou, China; ${ }^{6}$ GIN (Guidelines International Network) Asia, Lanzhou, China; ${ }^{7}$ Key Laboratory of Evidence Based Medicine and Knowledge Translation of Gansu Province, Lanzhou University, Lanzhou, China; ${ }^{8}$ The First School of Clinical Medicine, Lanzhou University, Lanzhou, China; ${ }^{9}$ School of Clinical Medicine, Chengdu Medical College, Chengdu, China; ${ }^{10}$ The Second School of Clinical Medicine, Chongqing Medical University, Chongqing, China; ${ }^{11}$ Department of Pediatric, Sichuan Provincial People's Hospital, University of Electronic Science and Technology of China, Chengdu, China; ${ }^{12}$ Chinese Academy of Sciences Sichuan Translational Medicine Research Hospital, Chengdu, China; ${ }^{13}$ School of Pharmacy, Chengdu Medical College, Chengdu, China; ${ }^{14}$ Department of Emergency Medicine, The General Hospital of Western Theater Command of PLA, Chengdu, China

Contributions: (I) Conception and design: P Du, W Chen, X Luo, S Yang, X Feng; (II) Administrative support: X Yang, Y Chen, S Yang, X Feng; (III) Provision of study materials or patients: P Du, Y Chen, X Luo, Q Shi; (IV) Collection and assembly of data: P Du, X Luo, Q Shi, M Lv, J Wang, X Shi; (V) Data analysis and interpretation: S Yang, X Feng, P Du, X Yang, X Ma, T Yang, T Li; (VI) Manuscript writing: All authors; (VII) Final approval of manuscript: All authors.

\#These authors contributed equally to this work.

Correspondence to: Dr. Xiaokun Yang. Department of Emergency Medicine, The General Hospital of Western Theater Command of PLA, No. 270 Rongdu Road, Chengdu, China. Email: bacelona1978@163.com; Dr. Shu Yang. College of Medical Information Engineering, Chengdu University of Traditional Chinese Medicine, No. 37, Twelve-bridge Road, Chengdu, China. Email: yangshu@cdutcm.edu.cn; Dr. Xixi Feng. School of Public Health, ChengDu Medical College, No. 783 Xindu Road, Chengdu, China. Email: fengxixi@163.com.

Backgroundk Corona virus disease 2019 (COVID-19) showed a significant difference in case fatality rate between different regions at the early stage of the epidemic. In addition to the well-known factors such as age structure, detection efficiency, and race, there was also a possibility that medical resource shortage caused the increase of the case fatality rate in some regions.

Methods: Medline, Cochrane Library, Embase, Web of Science, CBM, CNKI, and Wanfang of identified articles were searched through 29 June 2020. Cohort studies and case series with duration information on COVID-19 patients were included. Two independent reviewers extracted the data using a standardized data collection form and assessed the risk of bias. Data were synthesized through description and analysis methods including a meta-analysis.

Results: A total of 109 articles were retrieved. The time interval from onset to the first medical visit of COVID-19 patients in China was 3.38 \pm 1.55 days (corresponding intervals in Hubei province, non-Hubei provinces, Wuhan, Hubei provinces without Wuhan were 4.22 $\pm 1.13,3.10 \pm 1.57,4.20 \pm 0.97$, and $4.34 \pm 1.72$ days, respectively). The time interval from onset to the hospitalization of COVID-19 patients in China was 8.35 \pm 6.83 days (same corresponding intervals were $12.94 \pm 7.43,4.17 \pm 1.45,14.86 \pm 7.12$, and $5.36 \pm 1.19$ days, respectively), and when it was outside China, this interval was $5.27 \pm 1.19$ days.

Discussion: In the early stage of the COVID-19 epidemic, patients with COVID-19 did not receive timely treatment, resulting in a higher case fatality rate in Hubei province, partly due to the relatively insufficient and unequal medical resources. This research suggested that additional deaths caused by the out-of-control epidemic can be avoided if prevention and control work is carried out at the early stage of the epidemic. 
Trial Registration: CRD42020195606.

Keywords! Corona virus disease 2019 (COVID-19); first diagnosis; hospitalization; time interval; meta-analysis

Submitted Jul 18, 2021. Accepted for publication Sep 30, 2021.

doi: $10.21037 /$ apm-21-1975

View this article at: https://dx.doi.org/10.21037/apm-21-1975

\section{Introduction}

The corona virus disease 2019 (COVID-19) epidemic outbreak began in December 2019 (1-3). By the end of 2020 , the total number of confirmed cases worldwide had exceeded 80.64 million, and the death toll had exceeded 1.76 million (4). Currently, no specific medicine for the treatment of COVID-19 has been found globally $(5,6)$. The World Health Organization (WHO) recommended that the treatment of COVID-19 should be mainly based on supportive treatment, including oxygen therapy for severe patients and those at risk of serious diseases, and more advanced respiratory support for critically ill patients (7). Timely hospitalization is a significant factor in prognosis and the risk of disease and death, especially patients with underlying diseases or the elderly (8-10). The timely treatment mainly depends on whether the medical resources in the area where patients live are sufficient, meanwhile, to a certain extent, it also depends on the patient's willingness to pay a medical visit (11). Through the collection and analysis of articles, this research compared the time intervals from onset to first medical visit and onset to the hospitalization of COVID-19 patients in different regions and assessed the supply and demand status of medical resources, to provide an evidence-based reference for authorities to guide people's health-related behaviors during epidemics, to stem the spread of the disease, reduce health care burden and death rate. We present the following article in according with the Preferred Reporting Items for Systematic Reviews and Meta-Analyses (PRISMA) reporting checklist (available at https://apm.amegroups.com/article/view/10.21037/apm$21-1975 / \mathrm{rc})$.

\section{Methods}

\section{Search strategy}

This systematic review was registered in International prospective register of systematic reviews (PROSPERO) on June 29, 2020, with the protocol of CRD42020195606. Articles publishing before June 29, 2020, that reported medical information of COVID-19 patients were included in this research, the following databases were comprehensively searched, including the Cochrane Library, PubMed, EMBASE, Web of Science, CBM (China Biology Medicine disc), CNKI (China National Knowledge Infrastructure), and Wanfang database. The following search formulas were used in this research, including ("COVID 19" OR "COVID-19” OR "SARS-CoV-2" OR "2019 novel coronavirus" OR "2019-nCoV" OR "2019-CoV" OR "coronavirus disease 2019" OR "coronavirus disease-19" OR "Novel coronavirus" OR "2019-novel coronavirus") AND ("symptom onset" OR "illness onset" OR "first symptom" OR "onset of illness") AND ("admission" OR "hospitalization") AND ("see a doctor" OR "first medical visit" OR "first medical care" OR "visit hospital”). Besides, WHO, Chinese Center for Disease Control and Prevention (CCDC), National Health Commission of the People's Republic of China, USA National Institutes of Health Ongoing Trials Register (ClinicalTrials.gov), International Standard Randomized Controlled Trial Number (ISRCTN) registry, Google Scholar, the preprint servers medRxiv (https://www.medrxiv.org/) and bioRxiv (https://www. biorxiv.org/), and Social Science Research Network (SSRN, https://www.ssrn.com/index.cfm/en/) were also included as retrieval sources. The retrieval strategy for this research was reviewed by information experts.

\section{Inclusion and exclusion criteria}

Case series and cohort studies that reported the medical visit time of COVID-19 patients were included. Abstracts, case reports, letters, news, guidelines, comments, and articles that were unable to obtain all relevant data or full texts were excluded. There were no restrictions on language or publication status. 


\section{Article screening}

After deleting duplicates in all the retrieved articles, two reviewers (P Du and Q Shi) used EndNote to independently screen these articles in two steps. The first step was to filter the title and summary using predefined criteria. The second step was to review the articles that were likely to meet the requirements by reading the full text and determine whether they will be finally included. The reasons for the exclusion of all unqualified articles were recorded, PRISMA flowcharts were used to record the process of article screening, and screening objections were resolved through discussion or consultation with a third reviewer (X Luo).

\section{Data extraction}

Data were extracted independently by two reviewers (P Du and Q Shi) using a standardized data collection form, and all objections were resolved through discussion or consultation with a third reviewer (X Luo). The third reviewer was responsible for checking the consistency and accuracy of the data. Data extraction includes the following three aspects: (I) basic information (title, author, country, date of publication, research type), (II) patient information (number, gender, age, disease type, sample size, grouping variables), (III) result information (the interval from first symptom onset to the first medical visit, the interval from the first symptoms onset to the first hospitalization, clinical outcome).

\section{Data analysis}

The $1^{\text {st }}$ time interval was defined as the interval from the first symptom onset to the first medical visit of COVID-19 patients, and the $2^{\text {nd }}$ time interval was defined as the interval from the first symptoms onset to the first hospitalization of COVID-19 patients. The medical institution was defined as the designated hospitals which are accredited for COVID-19 detection and treatment, since general clinics and isolation sites are unable to provide systematic measures. The clinical classification of COVID-19 patients in China is based on Guidelines on the Novel CoronavirusInfected Pneumonia Diagnosis and Treatment issued by the National Health Commission of People's Republic of China (12). A mild case was defined as mild clinical symptoms and no radio graphic evidence of pneumonia. A moderate case was defined as a confirmed case with fever, respiratory symptoms and radio graphic evidence of pneumonia. A severe case was defined as a confirmed case meets any of the following criteria: (I) shortness of breath, $\mathrm{RR} \geq 30$ times/min; (II) oxygen saturation $\leq 93 \%$ at rest; (III) alveolar oxygen partial pressure/fraction of inspiration $\mathrm{O} 2(\mathrm{PaO} 2 / \mathrm{FiO} 2)<300 \mathrm{mmHg}$. A critical case was defined as a confirmed case meets any of the following conditions: (I) respiratory failure requiring mechanical ventilation; (II) shock; (III) patients combined with other organ failure needed intensive care unit (ICU) monitoring and treatment. Exposure history was defined as COVID-19 patients with a history of travel to the source of the outbreak or a history of exposure to confirmed cases. The duration of viral shedding was defined as the number of days from the onset of the symptoms until the successive negative detection of SARSCoV-2 RNA.

\section{Statistical analysis}

In the retrieval articles, the statistics of the $1^{\text {st }}$ and $2^{\text {nd }}$ time intervals were described by mean \pm standard deviation or median (interquartile range), while some research only provided point estimates, maximum and minimum values. This research used an estimation method proposed by Luo (13) and Wan (14) et al. to unify the time intervals of all research as mean \pm standard deviation, and the sample size weighting method was used to calculate the weighted mean of each time interval sample. Linear or nonlinear regression was used to fit the trend of time interval of patients in different periods. The patients were divided into two groups according to the severity of the disease: common patients (mild and moderate cases) and severe patients (severe and critical cases) in the meta-analysis. Heterogeneity was defined as $\mathrm{P}<0.05$ and $\mathrm{I}^{2}>50 \%$ (15). Mean difference (MD) with $95 \%$ confidence intervals (CI) was used as the effect size. Sensitivity analysis was conducted by comparing the difference between the fixed-effect model and the random effect model. Two-sided $\mathrm{P}$ values $<0.05$ were considered statistically significant. All statistical analysis was implemented on RStudio (Version 1.2.5033).

\section{Assessment of risk of bias}

Two reviewers (P Du and Q Shi) independently assessed the risk of bias for each research, resolved objections by discussion, and consulted a third reviewer (X Luo) if necessary. Appropriate assessment tools were selected to assess the risk of bias according to research types in the article: the Newcastle-Ottawa scale which consists of eight parts, with each part using a star rating, should 


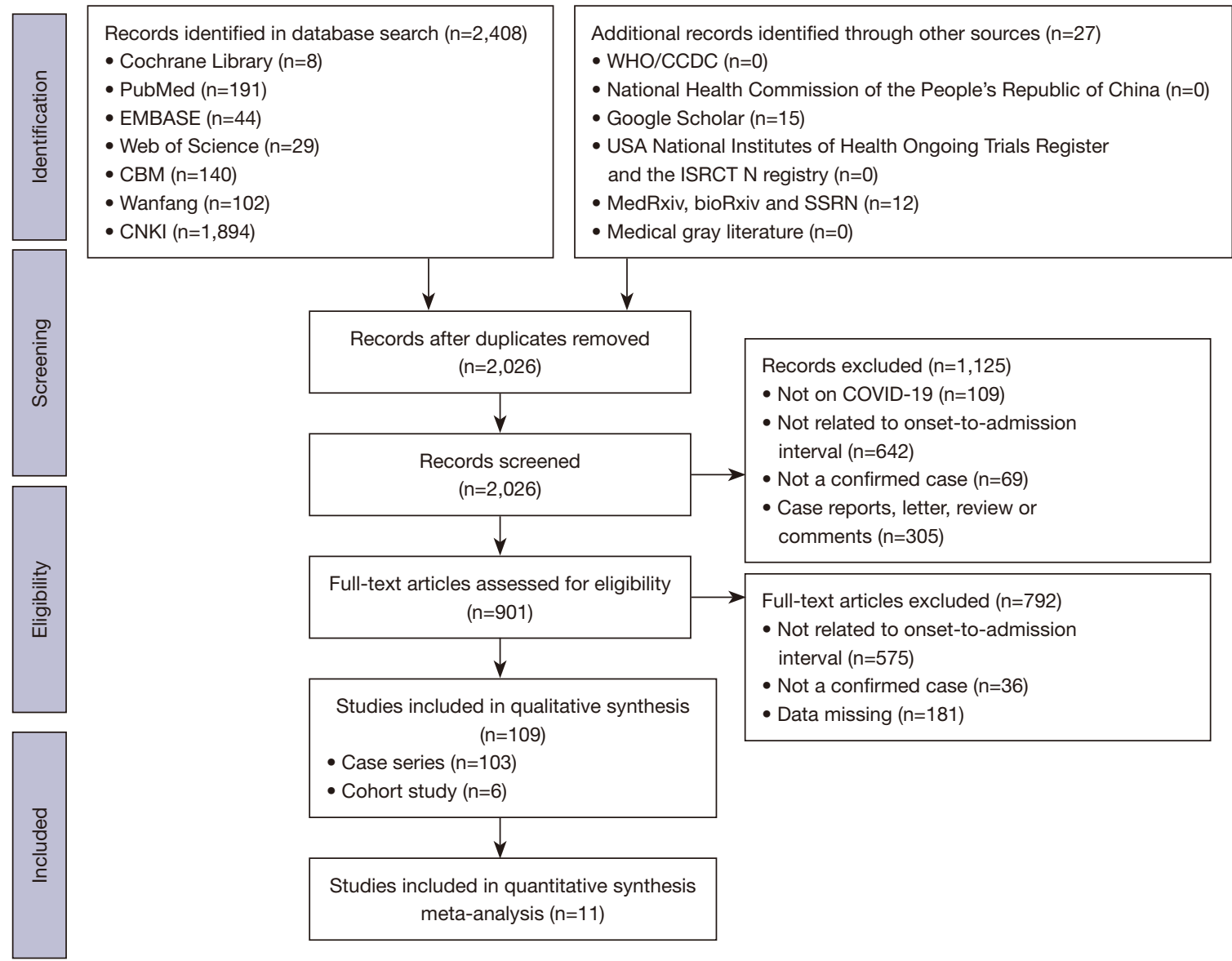

Figure 1 The processes of article retrieval and screening.

be used for the cohort study (16). The more the stars, the lower the risk of bias. Furthermore, for a case series study, methodological assessment tools recommended by the National Institute for Health and Care Excellence (NICE) should be used (17). The risk of bias was assessed against 8 criteria, and the results were summarized using a scoring method with 1 point for "Yes" and 0 point for "No". The higher the scores, the lower the risk of bias.

\section{Quality of evidence assessment}

Two reviewers (P Du and Q Shi) used Grading of Recommendations Assessment, Development and Evaluation (GRADE) guidelines $(18,19)$ to independently assessed the quality of evidence and used GRADEpro to create a form, in which the results of each research included in the meta-analysis were classified for evidence quality.
The overall quality was downgraded based on 5 factors (risk of bias, inconsistency, imprecision, indirectness, and publication bias) and upgraded based on 3 factors (large effect size, dose-effect relationship, and negative bias). The overall quality of evidence was classified as high, medium, low, or very low, reflecting the trust degree that the effect estimates were accurate.

\section{Results}

\section{Article research results}

After a systematic retrieval, 2,435 articles were retrieved for the first time. After deleting duplicates, 109 articles were finally included in the evaluation through screening titles, abstracts, and full texts, including 103 case series and 6 cohort studies, and the patient information of 101 articles (92.7\%) was collected before April 2020. The processes of article retrieval and screening were shown in Figure 1. 


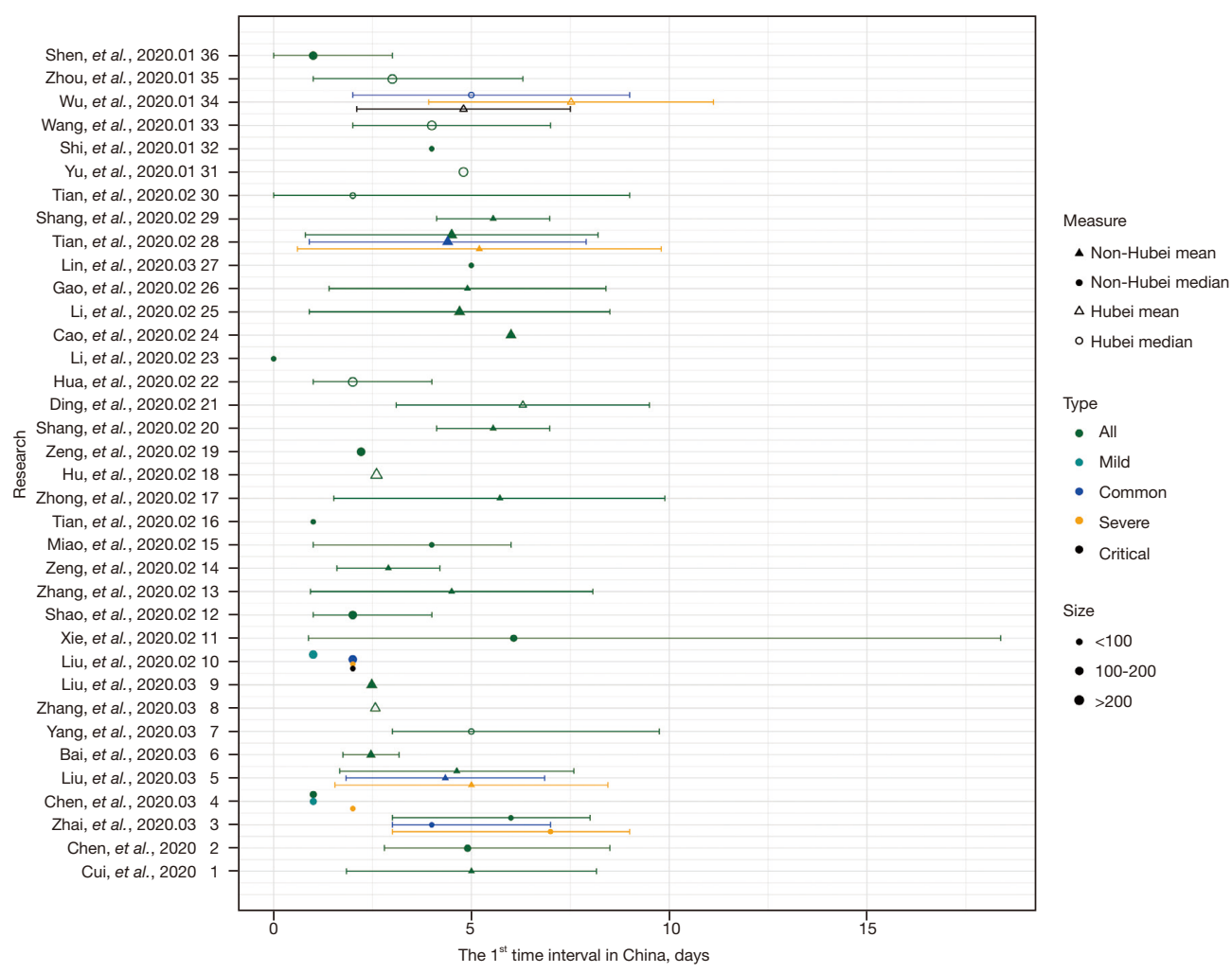

Figure 2 The distribution of the $1^{\text {st }}$ time interval of COVID-19 patients in China. The articles are sorted by the follow-up time end date, with the most recent at the top. Hollow points and solid points represented articles from Hubei province and non-Hubei provinces respectively. The mean was represented by a triangle and the median was represented by a circle. The length of a line segment was determined by the standard deviation of the interval and the interquartile spacing, and the point estimate had no corresponding line segment. Patients with different severity of disease were shown in different colors. The sample size was represented by the size of the points. COVID-19, corona virus disease 2019.

A total of 18,777 patients were included in this research, including 8,405 females (44.8\%), 9,671 males (51.5\%), and 701 patients $(3.7 \%)$ with unknown gender. China contributed 100 (91.7\%) articles, 38 (34.9\%) of which were from Hubei province (the most affected province in China). The remaining $9(8.3 \%)$ articles were from abroad shown in Table S1 [two articles from Singapore (20,21), two articles from Korea $(22,23)$, two articles from the United States $(24,25)$, one article from Germany (26), one article from Japan (27) and 1 article from French (28)].

This research intended to assess whether the patient had received treatment in time by collecting the $1^{\text {st }}$ and $2^{\text {nd }}$ time intervals. Among the included 109 articles, 30 articles only reported the $1^{\text {st }}$ time interval, 73 articles only reported the $2^{\text {nd }}$ time interval, and 6 articles reported both time intervals. The included articles' assessment of the risk of bias was provided in Tables S2,S3.

\section{Time interval from onset to the first medical visit}

Figure 2 showed the $1^{\text {st }}$ time interval in 36 articles, of which 10 articles $(27.8 \%)$ were from Hubei Province and 26 articles $(72.2 \%)$ were from non-Hubei provinces. The $1^{\text {st }}$ time interval was not mentioned in the included articles outside China. The $1^{\text {st }}$ time interval was mostly concentrated in about 5 days, the minimum time interval was 0 (median) days [an article from Shenyang, China (29), 65.38\% (17 out of 26) of COVID-19 patients paid a medical visit on the day of onset), the maximum time interval was 7.52 (mean) days (an article from Hubei Province researching on severe patients (30)]. In terms of the $1^{\text {st }}$ time interval, no significant difference was found between patients from Hubei province and non-Hubei provinces.

Part of the articles made statistics of COVID-19 patients' $1^{\text {st }}$ time interval in groups according to the severity of the 
disease, exposure history, time around Wuhan's cordon sanitaire, etc. Firstly, 6 articles grouped patients according to the severity of the disease, and the results showed that the longer the $1^{\text {st }}$ time interval, the worse the patient's health condition. However, a research of Wuhan showed that the $1^{\text {st }}$ time interval in severe patients ( 7.52 days) was longer than that in common patients (5.35 days), whereas the $1^{\text {st }}$ time interval of critically ill patients was shorter (4.8 days) (30). Secondly, an article from Shenyang grouped patients according to whether they had an exposure history, and the result showed that patients without an exposure history (4 days) had a longer $1^{\text {st }}$ time interval compared with those who had one (0 days) (29). Thirdly, an article from Hunan province indicated that the $1^{\text {st }}$ time interval of patients after January 23 (cordon sanitaire day of Wuhan) (1 day) was shorter than that before January 23 (3 days) (31).

\section{Time interval from onset to bospitalization}

Figure 3 showed the $2^{\text {nd }}$ time interval in 70 articles, of which $31(44.3 \%)$ articles were from Hubei province (27 articles from Wuhan), and 39 (55.7\%) articles were from nonHubei provinces. The $2^{\text {nd }}$ time interval was 1 (median) day to 25.9 (mean) days among the 70 articles, the minimum value appeared in an article from non-Hubei provinces (32) and the maximum value appeared in an article from Wuhan that researched 55 COVID-19 patients' delayed treatment cases (33). The $2^{\text {nd }}$ time interval of Hubei COVID-19 patients was 3 days to 25.9 days, and it was 1 day to 8.5 days for non-Hubei COVID-19 patients. In general, COVID-19 patients in Hubei province had a longer $2^{\text {nd }}$ time interval than those in non-Hubei provinces. Equally, an included article showed the same research result (5.7 days in Hubei province and 4.5 days in non-Hubei provinces) after compared the $2^{\text {nd }}$ time interval in 647 patients from Hubei province and 943 patients from non-Hubei provinces (34).

Part of the articles made statistics of COVID-19 patients' $2^{\text {nd }}$ time interval in groups according to clinical outcome, the severity of the disease, and the duration of viral shedding. There were 4 articles from Hubei province dividing COVID-19 patients into two groups (cure and death) according to clinical outcome. Two of them indicated that the $2^{\text {nd }}$ time interval of the cured group was shorter than that of the dead group clearly $(35,36)(3$ days $/ 5$ days and 7 days/10 days in the 2 articles respectively). Additionally, 8 articles grouped patients according to the severity of the disease, and the results showed that the longer the $2^{\text {nd }}$ time interval, the worse the patients' health condition. Moreover, 3 articles grouped patients by the duration of viral shedding (37-39), and the results showed that the longer the $2^{\text {nd }}$ time interval, the longer the duration of viral shedding.

Figure 4 summarized the $2^{\text {nd }}$ time interval in 9 articles outside China, ranging from 3.5 days to 8 days. An article from South Korea divided COVID-19 patients into two groups according to whether they were admitted to the ICU, and results showed that the $2^{\text {nd }}$ time interval of the patients admitted to the ICU (4.7 days) was shorter than the patients did not admit to the ICU (8.2 days) (23). A German article divided COVID-19 patients into two groups according to whether they had ARDS, and the results showed that the $2^{\text {nd }}$ time interval of ARDS patients (7 days) was longer than common patients (3 days) (26).

\section{Estimation of the $1^{\text {st }}$ time interval and the $2^{\text {nd }}$ time interval}

Figure $5 A$ indicated the daily number of newly confirmed COVID-19 cases in Wuhan, Hubei province without Wuhan and non-Hubei provinces from January 20, 2020 to March 10, 2020. As shown in the figure, most of the new cases confirmed in the early and middle of February. In Figure $5 B$ and $5 C$, this research took the median followup time point as the horizontal axis, and the $1^{\text {st }}$ and $2^{\text {nd }}$ time intervals were taken as the vertical axis to draw scatter plots. There was a decreasing trend for the $1^{\text {st }}$ time interval in Wuhan, and no obvious trend in non-Hubei provinces or Hubei province without Wuhan. Figure $5 C$ showed that the $2^{\text {nd }}$ time interval of COVID-19 patients had a relatively obvious trend of gradual increase since February in Wuhan. Non-Hubei provinces had a trend of decrease, and no obvious trend was observed in Hubei province without Wuhan because only four articles were included.

Through research, the $1^{\text {st }}$ time interval of COVID-19 patients in China was approximately $3.38 \pm 1.55$ days, with a median of $2.60(2.35,4.70)$ days. In Hubei province, it was $4.22 \pm 1.13$ days, with a median of $4.35(3.46,4.84)$ days. In non-Hubei provinces, it was $3.10 \pm 1.57$ days, with a median of $2.48(2.31,4.50)$ days. In Hubei province without Wuhan, it was $4.34 \pm 1.72$ days, with a median of 3.79 (2.57, $5.35)$ days. In Wuhan, it was $4.20 \pm 0.97$ days, with a median of $4.35(3.46,4.84)$ days. There was no estimation of patients' the $1^{\text {st }}$ time interval outside China due to a lack of relevant data.

The $2^{\text {nd }}$ time interval of COVID-19 patients was 


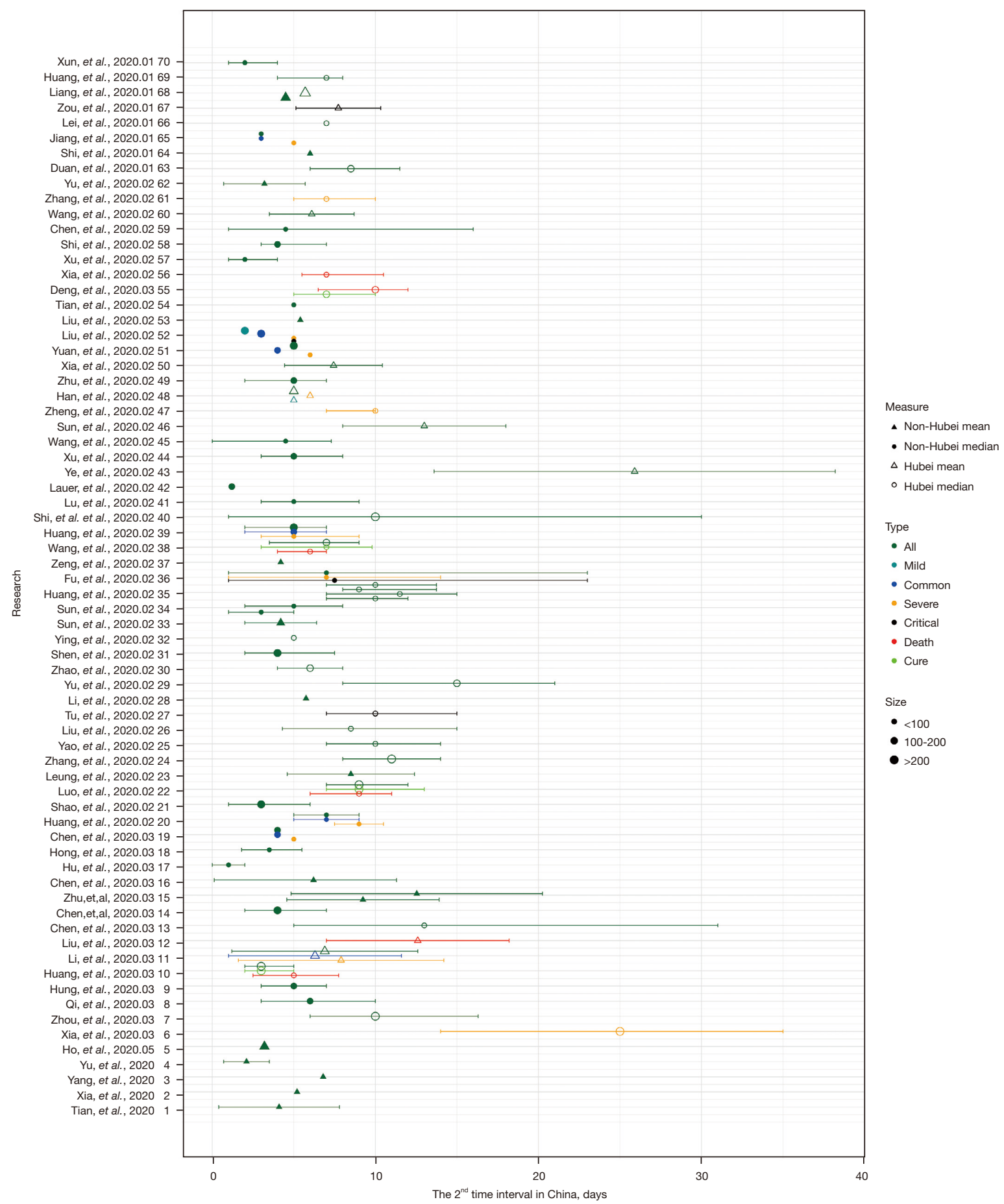

Figure 3 The distribution of the $2^{\text {nd }}$ time interval of COVID-19 patients in China. The description was the same as Figure 2 except for the $2^{\text {nd }}$ time interval. COVID-19, corona virus disease 2019. 


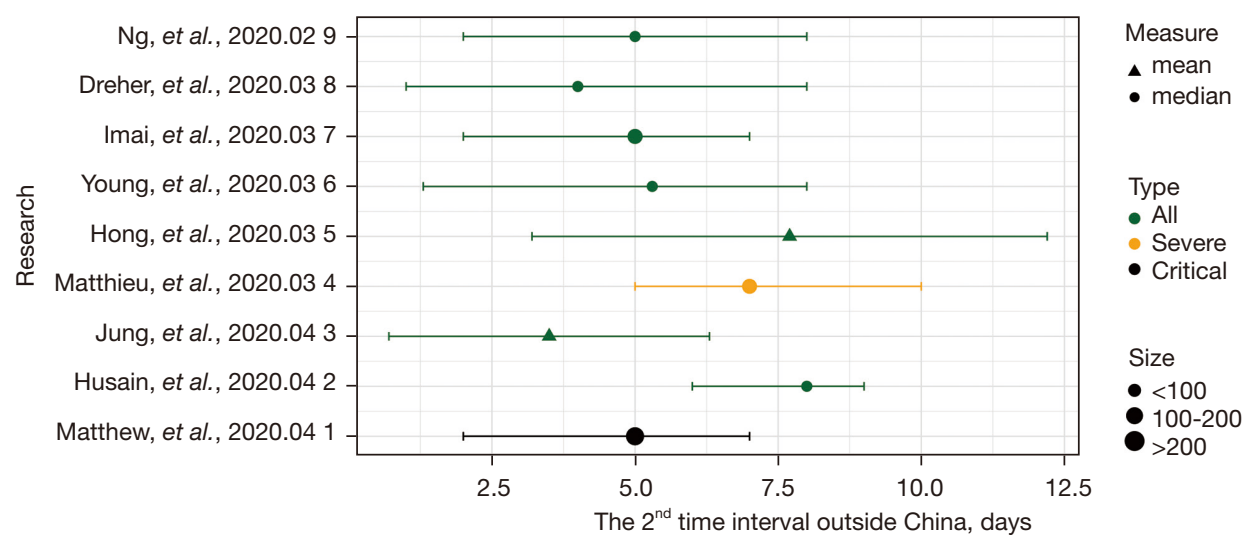

Figure 4 The distribution of the $2^{\text {nd }}$ time interval of COVID-19 patients outside China. The articles are sorted by the follow-up time end date, with the most recent at the top. Hollow points and solid points represented articles from Hubei province and non-Hubei provinces. The mean was represented by a triangle and the median was represented by a circle. The length of a line segment was determined by the standard deviation of the interval and the interquartile spacing. The sample size was represented by the size of the points. COVID-19, corona virus disease 2019.

A

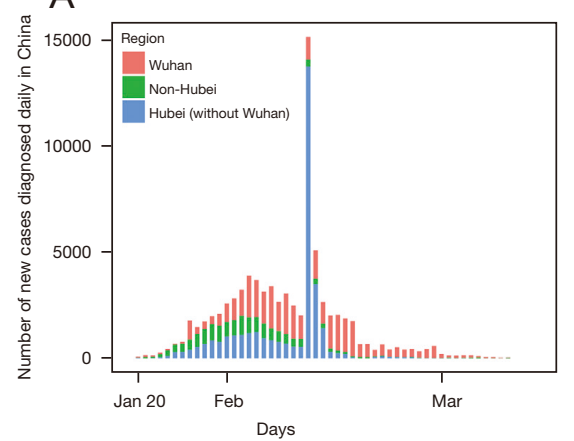

B

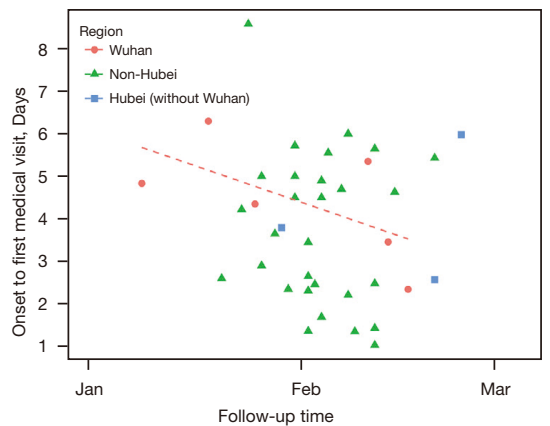

C

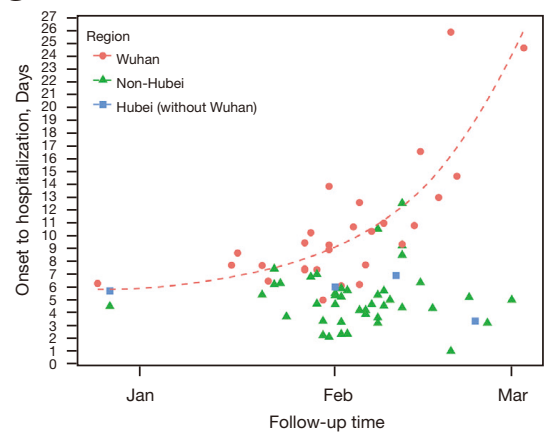

Figure 5 Estimation of the $1^{\text {st }}$ time interval and the $2^{\text {nd }}$ time interval in China. (A) was a stacked histogram of the number of daily new confirmed COVID-19 cases in Wuhan, Hubei province without Wuhan, and non-Hubei provinces from January 20, 2020 to March 10, 2020. (B) was a scatter plot of the median follow-up time point and the $1^{\text {st }}$ time interval. (C) was a scatter plot of the median follow-up time point and the $2^{\text {nd }}$ time interval. COVID-19, corona virus disease 2019.

approximately $8.35 \pm 6.83$ days, with a median of 5.39 (3.35, 10.54) days. In Hubei province, it was $12.94 \pm 7.43$ days, with a median of $10.81(6.90,24.65)$ days. In non-Hubei provinces, it was $4.17 \pm 1.45$ days, with a median of 4.35 (3.20, 4.65) days. In Hubei province without Wuhan, it was $5.36 \pm 1.19$ days, with a median of $5.7(5.70,6.00)$ days. In Wuhan, it was $14.86 \pm 7.12$ days, with a median of 11.00 $(9.35,24.65)$ days. Outside China, it was $5.27 \pm 1.19$ days, with a median of $4.65(4.65,5.00)$ days.

\section{Meta-analysis of the time interval of common patients and severe patients}

Six articles from China [one article (30) from Hubei province and five articles $(31,40-43)$ from non-Hubei provinces] had reported the $1^{\text {st }}$ time interval according to the severity of disease of COVID-19 patients. the meta-analysis results showed that compared with common patients, the $1^{\text {st }}$ time interval of severe patients was longer $\mathrm{MD}=-1.25,95 \%$ 


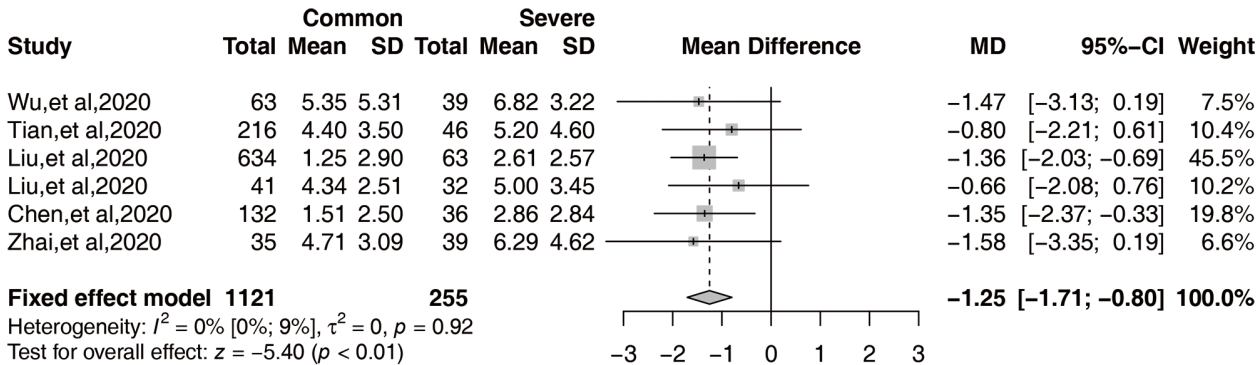

Figure 6 Meta-analysis of the $1^{\text {st }}$ time interval of common and severe patients.

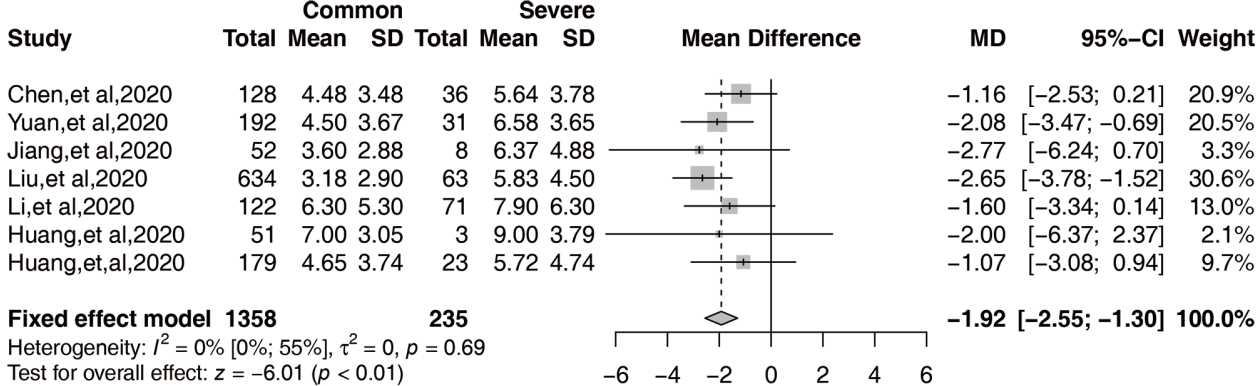

Figure 7 Meta-analysis of the $2^{\text {nd }}$ time interval of common and severe patients.

Table 1 Sensitivity-analysis of the time interval of common patients and severe patients

\begin{tabular}{lcr}
\hline Research factors & Fixed effect model, MD (95\% Cl) & Random effect model, MD (95\% Cl) \\
\hline Duration from symptom onset to first medical visit & $-1.25(-1.71,-0.80)$ & $-1.25(-1.71,-0.80)$ \\
Duration from symptom onset to admission & $-1.92(-2.55,-1.30)$ & $-1.92(-2.55,-1.30)$ \\
\hline
\end{tabular}

$\mathrm{MD}$, mean difference; $\mathrm{Cl}$, confidence interval.

CI (-1.71, -0.80), $\mathrm{P}<0.01, \mathrm{I}^{2}=0 \%$ (Figure 6).

Eight articles from China [two articles $(44,45)$ from Hubei province and six articles $(31,41,46-49)$ from nonHubei provinces] had reported the $2^{\text {nd }}$ time interval according to the severity of disease of COVID-19 patients. One of the eight articles (44) showed that the $2^{\text {nd }}$ time interval for severe patients and common patients in Wuhan were 6 and 5 days, respectively, however, it was excluded from the meta-analysis since it only provided a point estimate. The meta-analysis results showed that compared with common patients, the $2^{\text {nd }}$ time interval of severe patients was longer $\mathrm{MD}=-1.92,95 \%$ CI $(-2.55,-1.30)$,
$\mathrm{P}<0.01, \mathrm{I}^{2}=0 \%$ (Figure 7 ).

\section{Sensitivity analysis and quality of evidence}

By comparing the difference between the fixed-effect model and the random effect model, the results of the sensitivity analysis showed that MD values and 95\% CI results were close either in the $1^{\text {st }}$ time interval or in the $2^{\text {nd }}$ time interval, which indicated that the meta-analysis in this research was stable. The details of the sensitivity analysis can be found in Table 1.

The qualities of the evidence included in the articles 
were very low according to the GRADE quality assessment. Details were provided in Table S4.

\section{Discussion}

COVID-19 was a highly infectious emerging disease that had caused a global pandemic (50). The rapid development of the epidemic had exposed the deficiencies in epidemic prevention and control, public health systems, and health care systems of various countries. In some areas, the unequal allocation of medical resources directly led to the delay of patient medical visits and treatment (51).

The results of this research showed that the $1^{\text {st }}$ time interval of COVID-19 patients in China was 0 days to 7.52 days, with an estimated value of $3.38 \pm 1.55$ days, and it was $4.22 \pm 1.13$ days in Hubei Province and 3.10 \pm 1.57 days in non-Hubei provinces. Overseas articles did not involve the time data. The $1^{\text {st }}$ time interval was approximately 1 day longer for COVID-19 patients in Hubei than in non-Hubei areas, whereas the time interval between Wuhan and the rest of Hubei province was relatively similar. This indicated that people in Hubei province had poorer access to health care than other provinces during the outbreak, which had further contributed to the spread of COVID-19 there.

The lack of public awareness of COVID-19 at the beginning of the epidemic, coupled with the fact that most SARS-CoV-2 infected individuals have mild symptoms and the early clinical manifestations of the disease are difficult to distinguish from the common cold, might lead infected individuals to ignore the initial mild symptoms and not pay a timely medical visit. As shown in Figure 5B, the cordon sanitaire policies implemented from January 23 in Wuhan had strengthened people's attention to COVID-19, and the $1^{\text {st }}$ time interval had been significantly shortened after these cordon sanitaire policies (31). Therefore, timely disclosure of the outbreak and strong preventive and control measures can help raise the awareness of the public.

At the end of January, China implemented the highest level of public health emergency response policies, including quarantine and medical observation for people with an exposure history, case tracing, and screening of close contacts. An article from Shenyang showed that the $1^{\text {st }}$ time interval of patients with an exposure history was shorter than that of those without an exposure history, which was related to these policies (29). Nevertheless, the outbreak of COVID-19 caused a certain degree of social panic, and some suspected patients were afraid of paying a medical visit and handled by themselves through home isolation, which was also a reason leading to the delay of patients' medical visits and treatment $(52,53)$. Therefore, during the critical period of epidemic prevention and control, national and local authorities should disclose information in an understandable, timely, transparent and coordinated manner to reduce public panic. At the same time, the authorities should strengthen epidemiological investigation, health education, public awareness of medical visits, to urge the patients to pay a medical visit in time.

The $2^{\text {nd }}$ time interval of COVID-19 patients in China was 1 to 15 days, with an estimated value of $8.35 \pm 6.83$ days, and it was $12.94 \pm 7.43$ days in Hubei Province, and 4.17 \pm 1.45 days in non-Hubei provinces. The $2^{\text {nd }}$ time interval outside China was 3 days to 8 days, with an estimated value of $4.89 \pm 0.89$ days. If the regional disparities in the $2^{\text {nd }}$ time interval of COVID-19 patients between China and outside China might be influenced by lifestyle, health systems, and patient treatment (26), then the more obvious differences among multiple regions in China were more likely due to the variances in the supply and demand status of medical resources. The mean of the $2^{\text {nd }}$ time interval in Hubei provinces was obviously longer and the standard deviation was strongly bigger than those non-Hubei provinces of China may indicate that Hubei Province had not only the longest $2^{\text {nd }}$ time interval but also a huge difference in system composition compared with other regions. Figure $5 B$ showed that there was a slight difference in the $1^{\text {st }}$ time interval of patients between Wuhan and non-Hubei provinces, while Figure $5 C$ showed that the $2^{\text {nd }}$ time interval of patients in Wuhan was significantly longer than that in non-Hubei provinces, and the trend of increasing over time in Figure $5 \mathrm{C}$ could be considered consequently caused by medical overwhelmed in Wuhan with the rapid accumulation of cases $(48,54)$. Therefore, the length of the 2nd time interval, to some extent, reflected the inadequacy of medical resources in Wuhan during the health emergency. However, as a provincial capital city, the number of tertiary hospitals in Wuhan ranked ahead in China (55), and the proportion of medical staffs (10.19 health technical personnel per thousand, 3.69 licensed physicians per thousand, 5.07 registered nurses per thousand) were much higher than national average level, in which corresponding numbers were 7.26, 2.77 and 3.18 (56,57). If the outbreak is out of control at the initial stage, the shortage of medical resources in a specific period cannot be avoided even in an area with relatively sufficient self-resource reserves and 
supplements mobilized from other areas.

Of the 109 articles included, 6 articles compared the $1^{\text {st }}$ time interval, and 8 articles compared the $2^{\text {nd }}$ time interval in COVID-19 patients with various disease severities. The results showed that both time intervals were longer in patients with severe disease than in patients with mild disease and common patients. Meta-analysis comparing the length of the $2^{\text {nd }}$ time interval between common patients and severe patients revealed that delayed hospitalization may be an influential factor in the exacerbation of the patient's condition. Although one research from Wuhan reported a shorter the $1^{\text {st }}$ time interval in critically ill patients than in the common patients, this may be related to the fact that the average age of critically ill patients (69 yrs old) is higher than that of the common patients (43 yrs old) (30), and numerous researches have confirmed the strong correlation between age and severity of disease in patients with COVID-19 (6). Some research indicated that delayed treatment would also affect virus shedding time (37), resulting in a higher risk of infection among close contacts, easy spread, and the occurrence of cluster outbreaks, which was not conducive to the national epidemic prevention and control.

\section{Advantages and limitations}

This research analyzed whether COVID-19 patients receive treatment in time by summarizing the $1^{\text {st }}$ and $2^{\text {nd }}$ time intervals from the 109 articles. In terms of advantages, our research demonstrated the supply and demand status of medical resources in the early stage of the epidemic by comparing the differences in the $1^{\text {st }}$ time interval and the $2^{\text {nd }}$ time interval of patients in different regions and with various disease severities, to analyze whether there is an increase in case fatality rate caused by insufficient medical resources and provide a reference for national or regional medical resource allocation, personnel scheduling, and prevention and control policy decisions.

The research had several limitations. Firstly, only nine articles outside China were included in this research, which may have caused some bias. Secondly, the estimation of time intervals may affect the accuracy of the research results due to the sample size weighting method and the conversion method of median to estimate the mean, as well as missing data in some articles. Thirdly, the progression of the patient's condition is not only related to the time of visit, but the patient's gender, age, physical health status, and the medical resources will lead to the bias of the results.

\section{Conclusions}

It was found that the $1^{\text {st }}$ time interval was similar between Hubei and non-Hubei patients, but the $2^{\text {nd }}$ time interval of Hubei was much longer than that of non-Hubei patients. The $2^{\text {nd }}$ time interval of COVID-19 patients outside China was close to that of non-Hubei provinces. Both the $1^{\text {st }}$ and $2^{\text {nd }}$ intervals were longer in severe patients than in common patients. This phenomenon supported that there was a medical overwhelmed resource and patients with COVID-19 did not receive timely treatment in Hubei province at the beginning of the epidemic, and this could explain why the case fatality rate in Hubei province was much higher than that in other parts of China at the beginning of the outbreak. Besides detection efficiency, the relative lack of medical resources was another important reason that was ignored.

\section{Acknowledgments}

We would like to thank all the primary authors of studies included in this systematic review and meta-analysis.

Funding: This work was supported by "Coronavirus Disease Special Project" of Xinglin Scholars of Chengdu University of Traditional Chinese Medicine (XGZX2013).

\section{Footnote}

Reporting Checklist: The authors have completed the PRISMA reporting checklist. Available at https://apm. amegroups.com/article/view/10.21037/apm-21-1975/rc

Conflicts of Interest: All authors have completed the ICMJE uniform disclosure form (available at https://apm. amegroups.com/article/view/10.21037/apm-21-1975/coif). The authors have no conflicts of interest to declare.

Ethical Statement: The authors are accountable for all aspects of the work in ensuring that questions related to the accuracy or integrity of any part of the work are appropriately investigated and resolved.

Open Access Statement: This is an Open Access article distributed in accordance with the Creative Commons Attribution-NonCommercial-NoDerivs 4.0 International License (CC BY-NC-ND 4.0), which permits the noncommercial replication and distribution of the article with the strict proviso that no changes or edits are made and the 
original work is properly cited (including links to both the formal publication through the relevant DOI and the license). See: https://creativecommons.org/licenses/by-nc-nd/4.0/.

\section{References}

1. Zhu N, Zhang D, Wang W, et al. A Novel Coronavirus from Patients with Pneumonia in China, 2019. N Engl J Med 2020;382:727-33.

2. Huang C, Wang Y, Li X, et al. Clinical features of patients infected with 2019 novel coronavirus in Wuhan, China. Lancet 2020;395:497-506.

3. World Health Organization. Coronavirus disease (COVID-19) outbreak; 2019. Available online: https:// www.who.int [accessed 24.12.20].

4. Coronavirus disease (COVID-19) Weekly Epidemiological Update and Weekly Operational Update. Available online: https://www.who.int/emergencies/diseases/novelcoronavirus-2019/situation-reports [accessed 26.12.20].

5. Bloch EM, Shoham S, Casadevall A, et al. Deployment of convalescent plasma for the prevention and treatment of COVID-19. J Clin Invest 2020;130:2757-65.

6. Wu Z, McGoogan JM. Characteristics of and Important Lessons From the Coronavirus Disease 2019 (COVID-19) Outbreak in China: Summary of a Report of 72314 Cases From the Chinese Center for Disease Control and Prevention. JAMA 2020;323:1239-42.

7. World Health Organization. (2020). COVID-19 Clinical management: living guidance. Available online: https:// www.who.int/publications/i/item/WHO-2019-nCoVclinical-2021-1

8. Du RH, Liu LM, Yin W, et al. Hospitalization and Critical Care of 109 Decedents with COVID-19 Pneumonia in Wuhan, China. Ann Am Thorac Soc 2020;17:839-46.

9. Chen N, Zhou M, Dong X, et al. Epidemiological and clinical characteristics of 99 cases of 2019 novel coronavirus pneumonia in Wuhan, China: a descriptive study. Lancet 2020;395:507-13.

10. Guan WJ, Ni ZY, Hu Y, et al. Clinical Characteristics of Coronavirus Disease 2019 in China. N Engl J Med 2020;382:1708-20.

11. Luo XM, Zhou W, Xia H, et al. Characteristics of SARSCoV-2 Infected Patients with Clinical Outcome During Epidemic Ongoing Outbreak in Wuhan, China[J]. SSRN Electronic Journal 2020.

12. National Health Commission. The Guidelines for the Diagnosis and Treatment of COVID-19 (Trial, 7th edition). Available online: http://www.gov.cn/zhengce/ zhengceku/2020-03/04/content_5486705.htm

13. Luo D, Wan X, Liu J, et al. Optimally estimating the sample mean from the sample size, median, mid-range, and/or mid-quartile range. Stat Methods Med Res 2018;27:1785-805.

14. Wan X, Wang W, Liu J, et al. Estimating the sample mean and standard deviation from the sample size, median, range and/or interquartile range. BMC Med Res Methodol 2014;14:135.

15. Cumpston M, Li T, Page MJ, et al. Updated guidance for trusted systematic reviews: a new edition of the Cochrane Handbook for Systematic Reviews of Interventions. Cochrane Database Syst Rev 2019;10:ED000142.

16. Wells G, Shea B, O'Connell D, et al. Newcastle-Ottawa Quality Assessment Scale--Case Control Studies. Available online: http://www.ohri.ca/programs/clinical_ epidemiology/oxford.asp

17. National Institute for Health and Care Excellence. Appendix 4. Quality assessment for Case series. 2013. Available online: https://www.nice.org.uk/guidance/cg3/ documents/appendix-4-quality-of-case-series-form2

18. Norris SL, Meerpohl JJ, Akl EA, et al. The skills and experience of GRADE methodologists can be assessed with a simple tool. J Clin Epidemiol 2016;79:150-158.e1.

19. Guyatt GH, Oxman AD, Vist GE, et al. GRADE: an emerging consensus on rating quality of evidence and strength of recommendations. BMJ 2008;336:924-6.

20. Young BE, Ong SWX, Ng LF, et al. Immunological and Viral Correlates of COVID-19 Disease Severity: A Prospective Cohort Study of the First 100 Patients in Singapore. SSRN Electronic Journal 2020.

21. Ng Y, Li Z, Chua YX, et al. Evaluation of the Effectiveness of Surveillance and Containment Measures for the First 100 Patients with COVID-19 in Singapore - January 2-February 29, 2020. MMWR Morb Mortal Wkly Rep 2020;69:307-11.

22. Jung HY, Lim JH, Kang SH, et al. Outcomes of COVID-19 among Patients on In-Center Hemodialysis: An Experience from the Epicenter in South Korea. J Clin Med 2020;9:1688.

23. Hong KS, Lee KH, Chung JH, et al. Clinical Features and Outcomes of 98 Patients Hospitalized with SARS-CoV-2 Infection in Daegu, South Korea: A Brief Descriptive Study. Yonsei Med J 2020;61:431-7.

24. Husain SA, Dube G, Morris H, et al. Early Outcomes of Outpatient Management of Kidney Transplant Recipients with Coronavirus Disease 2019. Clin J Am Soc Nephrol 2020;15:1174-8. 
25. Cummings MJ, Baldwin MR, Abrams D, et al. Epidemiology, clinical course, and outcomes of critically ill adults with COVID-19 in New York City: a prospective cohort study. Preprint. medRxiv. 2020;2020.04.15.20067157.

26. Dreher M, Kersten A, Bickenbach J, et al. The Characteristics of 50 Hospitalized COVID-19 Patients With and Without ARDS. Dtsch Arztebl Int 2020;117:271-8.

27. Imai K, Tabata S, Ikeda M, et al. Clinical evaluation of an immunochromatographic IgM/IgG antibody assay and chest computed tomography for the diagnosis of COVID-19. J Clin Virol 2020;128:104393.

28. Mahévas M, Tran VT, Roumier M, et al. Clinical efficacy of hydroxychloroquine in patients with covid-19 pneumonia who require oxygen: observational comparative study using routine care data. BMJ 2020;369:m1844.

29. Li J, Gong J, Yao M, et al. Epidemiological characteristics of COVID-19 patients in Shenyang. Anhui Medical Journal 2020;41:254-6.

30. $\mathrm{Wu} \mathrm{W}$, Huang $\mathrm{H}$, Zhang $\mathrm{M}$, et al. Clinical features of COVID-19 patients:A 102 -case study. The Journal of Practical Medicine 2020;36:1569-73.

31. Liu Z, Gao L, Hu S, et al. Seeking health services and diagnosis of 697 confirmed cases of coronavirus disease 2019 in Hunan province. Pract Prev Med 2020;27:513-7.

32. Hu X, Xing Y, Jia J, et al. Factors associated with negative conversion of viral RNA in patients hospitalized with COVID-19. Sci Total Environ 2020;728:138812.

33. Ye J, Yu Y, Lu Y, et al. CT image characteristics and clinical analysis of 55 patients with Corona Virus Disease 2019 and delayed diagnosis and treatment. Medical Journal of Chinese People's Liberation Army 1-11[2020-12-04].

34. Liang WH, Guan WJ, Li CC, et al. Clinical characteristics and outcomes of hospitalised patients with COVID-19 treated in Hubei (epicentre) and outside Hubei (nonepicentre): a nationwide analysis of China. Eur Respir J 2020;55:2000562.

35. Huang J, Cheng A, Kumar R, et al. Hypoalbuminemia predicts the outcome of COVID-19 independent of age and co-morbidity. J Med Virol 2020;92:2152-8.

36. Deng Y, Liu W, Liu K, et al. Clinical characteristics of fatal and recovered cases of coronavirus disease 2019 in Wuhan, China: a retrospective study. Chin Med J (Engl) 2020;133:1261-7.

37. Xu K, Chen Y, Yuan J, et al. Factors Associated With Prolonged Viral RNA Shedding in Patients with Coronavirus Disease 2019 (COVID-19). Clin Infect Dis
2020;71:799-806.

38. Qi L, Yang Y, Jiang D, et al. Factors associated with the duration of viral shedding in adults with COVID-19 outside of Wuhan, China: a retrospective cohort study. Int J Infect Dis 2020;96:531-7.

39. Zhou Y, He X, Zhang J, et al. Prolonged SARSCoV-2 Viral Shedding in Patients with COVID-19 was Associated with Delayed Initiation of Arbidol Treatment: a retrospective cohort study. MedRxiv 2020. doi: 10.1101/2020.06.09.20076646.

40. Liu Y, Fan Y, Deng X, et al. Early warning factors of severe patients with COVID -19. The Journal of Practical Medicine 2020;36:1574-8.

41. Chen S, Jia P, Qiu L, et al. Epidemiological characteristics of COVID- - 19 in Hainan Province, China. Chinese Journal of Zoonoses 2020;36:372-6.

42. Tian S, Hu N, Lou J, et al. Characteristics of COVID-19 infection in Beijing. J Infect 2020;80:401-6.

43. Zhai H, Wu Q, Li W, et al. Analysis of the clinical characteristics of 74 cases with Corona Virus Disease 2019. Journal of Bengbu Medical College 2020;45:429-32.

44. Han J, Dong X, Hu F, et al. Clinical characteristics of 120 patients infected with SARS-CoV-2[J]. Guangdong Medical Journal 2020;41:772-5.

45. Li R, Tao J, Yao X, et al. Multi-Center Clinical Research of Risk Factors Associated with Severe and Critical Patients with Coronavirus Disease 2019. China Pharmaceuticals 2020;29:15-8.

46. Yuan J, Sun Y, Zuo Y, et al. Clinical characteristics of 223 COVID-19 patients in Chongqing. Journal of Southwest University (Natural Science Edition) 2020;42:17-24.

47. Huang Q, Deng X, Li Y, et al. Clinical characteristics and drug therapies in patients with the common-type coronavirus disease 2019 in Hunan, China. Int J Clin Pharm 2020;42:837-45.

48. Jiang Y, He S, Zhang C, et al. Clinical characteristics of 60 discharged cases of 2019 novel coronavirusinfected pneumonia in Taizhou, China. Ann Transl Med 2020;8:547.

49. Huang R, Zhu L, Xue L, et al. Clinical findings of patients with coronavirus disease 2019 in Jiangsu province, China: A retrospective, multi-center study. PLoS Negl Trop Dis 2020;14:e0008280.

50. Li JY, You Z, Wang Q, et al. The epidemic of 2019-novelcoronavirus (2019-nCoV) pneumonia and insights for emerging infectious diseases in the future. Microbes Infect 2020;22:80-5.

51. Emanuel EJ, Persad G, Upshur R, et al. Fair Allocation 
of Scarce Medical Resources in the Time of Covid-19. N Engl J Med 2020;382:2049-55.

52. Centers for Disease Control and Prevention. Reducing Stigma. Available online: https://www.cdc.gov/ coronavirus/2019-ncov/daily-life-coping/reducingstigma.html

53. World Health Organization, UNICEF and the Red Cross. Social Stigma Associated with COVID-19: A guide to preventing and addressing social stigma. Available online: https://www.unicef.org/documents/social-stigmaassociated-coronavirus-disease-covid-19

54. Xu XW, Wu XX, Jiang XG, et al. Clinical findings in a group of patients infected with the 2019 novel coronavirus

Cite this article as: Du P, Chen W, Luo X, Chen Y, Shi Q, Lv M, Wang J, Shi X, Ma X, Yang T, Lu S, Li T, Yang X, Yang S, Feng X; on behalf of COVID-19 Evidence and Recommendations Working Group. Did patients with COVID-19 receive timely treatment in the early epidemic? -a systematic review and meta-analysis. Ann Palliat Med 2022;11(2):452-465. doi: 10.21037/apm-21-1975
(SARS-Cov-2) outside of Wuhan, China: retrospective case series. BMJ 2020;368:m606.

55. The Lancet. Emerging understandings of 2019-nCoV. Lancet 2020;395:311.

56. Wuhan Health and Health Care Development Bulletin 2019. Available online: http://wjw.wuhan.gov.cn/zwgk_28/ fdzdgknr/tjsj/202010/P020201026595334757948.pdf. Accessed December 20, 2020.

57. Compiled by National Bureau of Statistics of China.China Statistical Yearbook -2020. Beijing: China Statistics Press. Available online: http://www.stats.gov.cn/tjsj/ndsj/2020/ indexeh.htm. Accessed December 20, 2020. 
Table S1 Characteristics of included articles

\begin{tabular}{|c|c|c|c|c|c|c|}
\hline Study ID & Study location & Study type & Time & Sample size & Sex $(\%, \operatorname{man})$ & Age (year) \\
\hline Luo 2020 (11) & Wuhan & Case series & 2020/01/30-2020/02/25 & 403 & $193(47.9)$ & $56.0(39.0,68.0)^{\star \star}$ \\
\hline Young 2020 (20) & Singapore & Cohort study & 2020/01/22-2020/03/06 & 100 & $56(56.0)$ & $46.0^{*}$ \\
\hline Ng 2020 (21) & Singapore & Case series & 2020/01/02-2020/02/29 & 100 & $60(60.0)$ & $42.5^{\star}$ \\
\hline Jung 2020 (22) & South Korea & Case series & 2020/02/01-2020/04/01 & 14 & $6(42.9)$ & $63.5 \pm 14.5^{*}$ \\
\hline Hong 2020 (23) & South Korea & Case series & To 2020/03/29 & 98 & $38(38.8)$ & $55.4 \pm 17.1^{*}$ \\
\hline Husain 2020 (24) & The United States & Case series & 2020/03/13-2020/04/06 & 41 & 30 (73.2) & $49.0(41.0,63.0)^{\star \star}$ \\
\hline Cummings 2020 (25) & The United States & Cohort study & 2020/03/02-2020/04/01 & 257 & $171(66.5)$ & $62.0(51.0,72.0)^{\star \star}$ \\
\hline Dreher 2020 (26) & Germany & Case series & 2020/02/01-2020/03/01 & 50 & $33(66.0)$ & $65.0(58.0,76.0)^{\star \star}$ \\
\hline Imai 2020 (27) & Japan & Case series & 2020/02/11-2020/03/31 & 112 & $64(57.1)$ & $67.0(45.0,74.0)^{\star \star}$ \\
\hline Mahévas 2020 (28) & French & Case series & 2020/03/12-2020/03/31 & 173 & $125(72.3)$ & $60.0(52.0,68.0)^{\star \star}$ \\
\hline Gao 2020 (58) & Shanxi & Case series & 2020/01/21-2020/02/18 & 40 & $19(47.5)$ & $41.0 \pm 16.4^{*}$ \\
\hline Fu 2020 (59) & Chongqing & Case series & 2020/01/21-2020/02/25 & 51 & 27 (52.9) & $60.9 \pm 14.9^{\star}$ \\
\hline Liu 2020 (31) & Hunan & Case series & 2020/01/21-2020/02/13 & 697 & - & - \\
\hline Liu 2020 (60) & Wuhan & Case series & To $2020 / 03 / 11$ & 47 & $32(68.1)$ & - \\
\hline Huang 2020 (61) & Wuhan & Case series & 2019/12/29-2020/02/27 & 305 & $167(54.8)$ & $54.5 \pm 14.4^{*}$ \\
\hline Liu 2020 (40) & Guangdong & Case series & 2020/01/01-2020/03/31 & 73 & $37(0.5)$ & $52.2 \pm 15.6^{\star}$ \\
\hline Liu 2020 (62) & Henan & Case series & To $2020 / 02 / 08$ & 15 & $10(66.7)$ & $46.5^{\star}$ \\
\hline Han 2020 (44) & Wuhan & Case series & 2020/01/12-2020/02/16 & 120 & $63(52.5)$ & $53.0 \pm 14.0^{*}$ \\
\hline Yu 2020 (63) & Beijing & Case series & 2020/01/21-2020/02/25 & 50 & $32(64.0)$ & $40.0 \pm 18.4^{*}$ \\
\hline Xia 2020 (64) & Hunan & Case series & From 2020/01/16 & 33 & $19(57.6)$ & $39.0^{\star \star}$ \\
\hline Chen 2020 (41) & Hainan & Case series & 2020/01/22-2020/03/04 & 168 & $81(48.2)$ & $51.0^{\star \star}$ \\
\hline Ye 2020 (33) & Wuhan & Case series & 2020/02/15-2020/02/25 & 55 & $29(52.7)$ & $59 \pm 13.1^{*}$ \\
\hline Yang 2020 (65) & Jiangsu & Case series & - & 57 & $29(50.9)$ & $37.0^{\star \star}$ \\
\hline Li 2020 (66) & Henan & Case series & $2020 / 01 / 21-2020 / 02 / 24$ & 256 & $159(62.1)$ & - \\
\hline Cao 2020 (67) & Chongqing & Case series & 2020/01/24-2020/02/23 & 223 & $105(47.2)$ & $46.5 \pm 16.1^{*}$ \\
\hline Yuan 2020 (46) & Chongqing & Case series & $2020 / 01 / 24-2020 / 02 / 23$ & 223 & $106(47.5)$ & $46.5 \pm 16.1^{*}$ \\
\hline Zeng 2020 (68) & Chongqing & Case series & 2020/01/21-2020/02/25 & 353 & $193(54.7)$ & $46.3^{*}$ \\
\hline Chen 2020 (69) & Fujian & Case series & - & 111 & $57(51.4)$ & $49.5^{\star \star}$ \\
\hline Hu 2020 (70) & Hunan & Case series & 2020/01/01-2020/02/08 & 852 & $460(51.8)$ & $44.0^{\star \star}$ \\
\hline Zhang 2020 (71) & Hubei & Case series & 2020/02/06-2020/03/07 & 120 & $73(60.8)$ & - \\
\hline Yang 2020 (72) & Hubei & Case series & 2020/01/30-2020/03/21 & 40 & $22(55.0)$ & $51.2^{*}$ \\
\hline An 2020 (73) & Wuhan & Case series & 2020/01/24-2020/02/19 & 110 & $44(40.0)$ & - \\
\hline Liu 2020 (74) & Shanxi & Case series & 2020/01/23-2020/03/02 & 245 & $131(53.5)$ & $46.2^{\star}$ \\
\hline Li 2020 (29) & Liaoning & Case series & 2020/01/26-2020/02/29 & 26 & $14(53.9)$ & $43.9 \pm 11.9^{*}$ \\
\hline Shi 2020 (75) & Zhejiang & Case series & 2020/01/17-2020/01/29 & 65 & $37(57.0)$ & $42.0^{\star \star}$ \\
\hline Lei 2020 (76) & Wuhan & Case series & 2020/01/10-2020/01/30 & 51 & $25(49.0)$ & $55.0^{\star \star}$ \\
\hline Sun $2020(77)$ & Henan & Case series & 2020/01/24-2020/02/26 & 129 & $59(45.7)$ & $45.0^{\star \star}$ \\
\hline Bai 2020 (78) & Shanxi & Case series & 2020/01/01-2020/03/06 & 120 & $63(52.5)$ & $49.4 \pm 18.2^{*}$ \\
\hline Chen 2020 (79) & Jiangsu & Case series & 2019/12/01-2020/03/01 & 30 & $17(56.7)$ & $48.9 \pm 13.1^{*}$ \\
\hline Zhong 2020 (80) & Hainan & Case series & 2020/01/21-2020/02/10 & 62 & $40(64.5)$ & $51.8 \pm 13.5^{\star}$ \\
\hline Zhu 2020 (81) & Anhui & Case series & 2020/01/18-2020/03/08 & 79 & $44(55.7)$ & $56.1 \pm 12.7^{*}$ \\
\hline Li 2020 (45) & Hubei & Case series & 2020/01/21-2020/03/02 & 193 & $112(58.0)$ & $50.7 \pm 16.2^{*}$ \\
\hline Zhang 2020 (82) & Anhui & Case series & 2020/01/23-2020/02/15 & 36 & $20(55.6)$ & $(8,75)^{\star \star \star}$ \\
\hline Zhang 2020 (83) & Wuhan & Case series & 2020/01/19-2020/02/08 & 10 & $7(70.0)$ & $74.5^{\star \star}$ \\
\hline Xia 2020 (84) & Wuhan & Case series & 2020/01/15-2020/02/08 & 52 & $23(44.2)$ & $54.0 \pm 12.8^{*}$ \\
\hline Zheng 2020 (85) & Wuhan & Case series & 2020/01/01-2020/02/01 & 71 & $35(49.3)$ & $62.0(53.5,70.0)^{\star \star}$ \\
\hline Sun 2020 (86) & Wuhan & Case series & 2020/02/09-2020/02/27 & 51 & $27(52.9)$ & $68.0^{*}$ \\
\hline Sun $2020(87)$ & Henan & Case series & 2020/01/24-2020/02/16 & 150 & $67(44.7)$ & $45.0 \pm 16.0^{*}$ \\
\hline Xu 2020 (54) & Zhejiang & Case series & 2020/01/10-2020/01/26 & 62 & $35(56.5)$ & $41.0(32.0,52.0)^{\star \star}$ \\
\hline Tian 2020 (88) & Hubei & Case series & 2020/01/13-2020/02/13 & 25 & $11(44.0)$ & $38.0^{\star \star}$ \\
\hline Chen 2020 (89) & Guangdong & Case series & 2020/01/11-2020/02/02 & 12 & $8(66.7)$ & $63.0^{*}$ \\
\hline Yin 2020 (90) & Wuhan & Case series & 2020/01/31-2020/02/10 & 95 & $34(35.8)$ & $35.0^{\star \star}$ \\
\hline Yu 2020 (91) & Beijing & Case series & From 2020/01/21 & 40 & $26(65.0)$ & $39.9 \pm 18.2^{*}$ \\
\hline Cui 2020 (92) & Gansu & Case series & - & 8 & $5(62.5)$ & $40.1^{*}$ \\
\hline Shang 2020 (93) & Anhui & Case series & 2020/01/22-2020/02/19 & 36 & $21(58.3)$ & $38.6 \pm 10.6^{\star}$ \\
\hline Hao 2020 (94) & Zhejiang & Case series & $2020 / 01 / 17-2020 / 02 / 12$ & 788 & $407(51.6)$ & $46.0(35.0,55.8)^{\star \star}$ \\
\hline
\end{tabular}

Table S1 (continued) 
Table S1 (continued)

\begin{tabular}{|c|c|c|c|c|c|c|}
\hline Study ID & Study location & Study type & Time & Sample size & Sex $(\%$, man $)$ & Age (year) \\
\hline Wang 2020 (95) & Shandong & Case series & 2020/01/31-2020/02/12 & 26 & $11(42.3)$ & $42.0(34.0,53.0)^{\star \star}$ \\
\hline Tian 2020 (96) & Shandong & Case series & - & 37 & $17(45.9)$ & $44.3 \pm 16.7^{*}$ \\
\hline Xu 2020 (37) & Zhejiang & Case series & 2020/01/13-2020/02/19 & 113 & $66(58.4)$ & $52.0(43.0,63.0)^{\star \star}$ \\
\hline Zhu 2020 (97) & Anhui & Case series & 2020/01/24-2020/02/20 & 116 & $56(48.3)$ & $40.0(27.0,53.0)^{\star \star}$ \\
\hline Huang 2020 (47) & Hunan & Case series & $2020 / 01 / 17-2020 / 02 / 10$ & 54 & $28(51.9)$ & $41.0(31.0,51.0)^{\star \star}$ \\
\hline Jiang 2020 (48) & Zhejiang & Case series & 2020/01/16-2020/01/31 & 60 & $35(58.3)$ & $41.0^{\star \star}$ \\
\hline Xu 2020 (54) & Zhejiang & Case series & 2020/01/10-2020/02/26 & 62 & $35(56.5)$ & $41.0(32.0,52.0)^{\star \star}$ \\
\hline Huang 2020 (35) & Hubei & Case series & $2020 / 01 / 25-2020 / 03 / 24$ & 299 & $160(53.5)$ & $53.4 \pm 16.7^{*}$ \\
\hline Huang 2020 (2) & Wuhan & Case series & 2019/12/16-2020/01/02 & 41 & $30(73.2)$ & $49.0(41.0,58.0)^{\star \star}$ \\
\hline Lauer 2020 (98) & Outside of Hubei & Case series & 2020/01/04-2020/02/24 & 181 & $108(59.7)$ & $44.5(34.0,55.5)^{\star \star}$ \\
\hline Xie 2020 (99) & Shanghai & Case series & 2020/01/01-2020/02/15 & 105 & $54(51.4)$ & $44.1 \pm 18.1^{*}$ \\
\hline Shi 2020 (100) & Shanghai & Case series & 2020/01/20-2020/02/07 & 184 & 99 (53.8) & $49.0 \pm 15.0^{*}$ \\
\hline Hu 2020 (32) & Shandong & Cohort study & 2020/01/29-2020/03/12 & 59 & $28(47.5)$ & $46.0(33.0,57.0)^{\star \star}$ \\
\hline Liang 2020 (34) & China & Cohort study & $2019 / 11 / 21-2020 / 01 / 31$ & 1590 & $904(57.3)$ & $48.9 \pm 16.3^{*}$ \\
\hline Deng 2020 (36) & Wuhan & Case series & $2020 / 01 / 01-2020 / 02 / 21$ & 225 & $124(55.1)$ & - \\
\hline Hua 2020 (101) & Wuhan & Case series & 2020/02/07-2020/02/26 & 205 & $112(54.6)$ & $51.0(39.0,57.0)^{\star \star}$ \\
\hline Lu 2020 (102) & Jiangsu & Case series & $2020 / 01 / 23-2020 / 02 / 26$ & 28 & $17(60.7)$ & $48.3 \pm 13.5^{\star}$ \\
\hline Shen 2020 (103) & Shanghai & Case series & 2020/01/20-2020/02/29 & 325 & $168(51.7)$ & $50.0^{*}$ \\
\hline Tian 2020 (42) & Beijing & Case series & $2020 / 01 / 20-2020 / 02 / 10$ & 262 & $127(48.5)$ & $47.5(45.1,49.9)^{\star \star}$ \\
\hline Shi 2020 (104) & Wuhan & Case series & 2020/01/20-2020/02/10 & 416 & $205(49.3)$ & $64.0(21.0,95.0)^{\star \star}$ \\
\hline Hung 2020 (105) & Hongkong & Case series & $2020 / 02 / 10-2020 / 03 / 20$ & 127 & $68(53.5)$ & $52.0(32.0,62.0)^{\star \star}$ \\
\hline Zhao 2020 (106) & Hubei & Case series & 2020/01/16-2020/02/17 & 136 & $68(50.0)$ & $49.0(33.0,63.0)^{\star \star}$ \\
\hline Qi 2020 (38) & Guangdong & Cohort study & 2020/01/24-2020/03/08 & 147 & $80(54.4)$ & $42.0(35.0,54.0)^{\star \star}$ \\
\hline Yu 2020 (107) & Wuhan & Case series & $2020 / 02 / 13-2020 / 02 / 28$ & 129 & $56(43.4)$ & $64.0(56.0,69.0)^{\star \star}$ \\
\hline Zhou 2020 (39) & Wuhan & Cohort study & 2020/01/15-2020/03/15 & 238 & $102(42.9)$ & $55.5(35.0,67.3)^{\star \star}$ \\
\hline Xia 2020 (108) & Wuhan & Case series & 2020/02/04-2020/03/30 & 1568 & $797(50.8)$ & $63.0(55.0,71.0)^{\star \star}$ \\
\hline Miao 2020 (109) & Shanghai & Case series & $2020 / 01 / 12-2020 / 02 / 13$ & 54 & $28(51.9)$ & $45.1 \pm 13.4^{*}$ \\
\hline Huang 2020 (49) & Jiangsu & Case series & 2020/01/22-2020/02/10 & 202 & $116(57.4)$ & $44.0(33.0,54.0)^{\star \star}$ \\
\hline Lam 2020 (110) & Hongkong & Case series & $2020 / 01 / 23-2020 / 05 / 31$ & 1084 & $588(54.2)$ & $37.5^{*}$ \\
\hline Wang 2020 (111) & Wuhan & Case series & To $2020 / 02 / 10$ & 107 & $57(53.3)$ & $51.0(36.0,65.0)^{\star \star}$ \\
\hline Zeng 2020 (112) & Sichuan & Case series & 2020/01/16-2020/02/05 & 20 & $12(60)$ & $57.4 \pm 16.5^{\star}$ \\
\hline Zou 2020 (113) & Wuhan & Case series & 2020/01/01-2020/01/29 & 15 & $10(66.7)$ & $61.7 \pm 9.6^{*}$ \\
\hline Ding 2020 (114) & Wuhan & Case series & $2020 / 01 / 01-2020 / 02 / 03$ & 56 & $30(53.6)$ & $54.6 \pm 15.5^{\star}$ \\
\hline Li 2020 (115) & Henan & Case series & $2020 / 01 / 20-2020 / 02 / 17$ & 40 & $20(50.0)$ & $50.9^{*}$ \\
\hline Wu $2020(30)$ & Hubei & Case series & $2020 / 01 / 01-2020 / 03 / 22$ & 102 & 75 (73.5) & $51.6 \pm 19.3^{*}$ \\
\hline Wang 2020 (116) & Wuhan & Case series & 2020/01/20-2020/02/14 & 96 & $46(47.9)$ & - \\
\hline Zhai 2020 (43) & Anhui & Case series & 2020/01/22-2020/03/04 & 74 & $41(55.4)$ & $54.9 \pm 11.8^{*}$ \\
\hline Tian 2020 (117) & Jiangsu & Case series & 2020/01/23-2020/02/16 & 23 & $10(43.5)$ & $49.7 \pm 13.1^{*}$ \\
\hline Yu 2020 (118) & Wuhan & Case series & 2020/12/18-2020/01/29 & 608 & $398(65.5)$ & $60.2 \pm 8.7^{*}$ \\
\hline Tian 2020 (119) & Jiangsu & Case series & 2020/01/23-2020/02/10 & 26 & $14(53.9)$ & $47.9 \pm 13.1^{*}$ \\
\hline Shang $2020(120)$ & Anhui & Case series & 2020/01/22-2020/02/19 & 36 & $21(58.3)$ & $38.6 \pm 10.6^{*}$ \\
\hline Zeng 2020 (121) & Hunan & Case series & 2020/01/24-2020/02/19 & 79 & $41(51.9)$ & $45.9 \pm 12.7^{\star}$ \\
\hline Hong 2020 (122) & Guangdong & Case series & $2020 / 01 / 17-2020 / 03 / 01$ & 18 & $9(50.0)$ & $63.5(51.5,67.5)^{\star \star}$ \\
\hline Wang 2020 (123) & Wuhan & Case series & 2020/01/10-2020/02/08 & 312 & $145(46.5)$ & $52.0(42.0,62.0)^{\star \star}$ \\
\hline Lin 2020 (124) & Zhejiang & Case series & 2020/01/15-2020/02/05 & 71 & $22(31.0)$ & $50.3 \pm 14.6^{*}$ \\
\hline Tu 2020 (125) & Wuhan & Case series & 2020/01/10-2020/02/29 & 75 & $53(70.7)$ & $68.0(62.0,74.0)^{\star \star}$ \\
\hline Liu 2020 (126) & Wuhan & Case series & 2020/01/16-2020/02/15 & 64 & $23(35.9)$ & $35.0(29.0,43.0)^{\star \star}$ \\
\hline Chen 2020 (127) & Guangdong & Case series & 2020/01/20-2020/03/15 & 284 & $131(46.1)$ & $48.0(33.0,62.0)^{\star \star}$ \\
\hline Chen 2020 (128) & Wuhan & Case series & 2020/01/01-2020/03/02 & 30 & $14(46.7)$ & $60.5(32.0,77.0)^{\star \star}$ \\
\hline Yao 2020 (129) & Wuhan & Case series & $2020 / 01 / 26-2020 / 02 / 18$ & 55 & $37(67.3)$ & $70.7 \pm 13.5^{\star}$ \\
\hline Zhang 2020 (130) & Wuhan & Case series & $2020 / 01 / 20-2020 / 02 / 29$ & 564 & $286(50.7)$ & $60.0(48.0,67.0)^{\star \star}$ \\
\hline Duan 2020 (131) & Wuhan & Case series & $2020 / 01 / 01-2020 / 01 / 31$ & 116 & $58(50.0)$ & $62.5(55,68.3)^{\star \star}$ \\
\hline Leung 2020 (132) & Hongkong & Case series & $2020 / 01 / 26-2020 / 02 / 28$ & 50 & $23(46.0)$ & $55.2 \pm 19.5^{\star}$ \\
\hline
\end{tabular}

*, mean SD; ${ }^{* *}$, median (IQR); ${ }^{* \star}$, range; -, not report. 


\begin{tabular}{|c|c|c|c|c|c|c|c|c|c|}
\hline Study ID & Item 1 & Item 2 & Item 3 & Item 4 & Item 5 & Item 6 & Item 7 & Item 8 & Scores $^{\dagger \dagger}$ \\
\hline Luo 2020 (11) & No & Yes & Yes & Yes & No & Yes & Yes & Yes & 6 \\
\hline Ng 2020 (21) & No & Yes & Yes & Yes & No & Yes & Yes & Yes & 6 \\
\hline Jung 2020 (22) & Yes & Yes & Yes & Yes & No & Yes & Yes & No & 6 \\
\hline Hong 2020 (23) & No & Yes & Yes & Yes & No & Yes & Yes & Yes & 6 \\
\hline Husain 2020 (24) & No & Yes & Yes & Yes & No & Yes & Yes & Yes & 6 \\
\hline Dreher 2020 (26) & No & Yes & Yes & No & No & Yes & Yes & Yes & 5 \\
\hline Imai 2020 (27) & Yes & Yes & Yes & Yes & No & Yes & Yes & Yes & 7 \\
\hline Mahévas 2020 (28) & Yes & Yes & Yes & Yes & Yes & No & Yes & No & 6 \\
\hline Gao 2020 (58) & Yes & Yes & Yes & Yes & No & Yes & Yes & No & 6 \\
\hline Fu 2020 (59) & No & Yes & Yes & Yes & No & Yes & Yes & Yes & 6 \\
\hline Liu 2020 (31) & No & Yes & No & Yes & No & Yes & Yes & Yes & 5 \\
\hline Liu 2020 (60) & No & Yes & Yes & Yes & No & Yes & Yes & Yes & 6 \\
\hline Huang 2020 (61) & No & Yes & Yes & Yes & No & Yes & Yes & Yes & 7 \\
\hline Liu 2020 (40) & No & Yes & Yes & Yes & No & Yes & Yes & Yes & 6 \\
\hline Liu 2020 (62) & No & No & No & Yes & No & Yes & Yes & No & 3 \\
\hline Han 2020 (44) & Yes & Yes & No & No & No & No & Yes & No & 3 \\
\hline Yu 2020 (63) & No & Yes & Yes & Yes & No & Yes & Yes & Yes & 6 \\
\hline Xia 2020 (64) & No & Yes & Yes & Yes & No & Yes & Yes & Yes & 6 \\
\hline Chen 2020 (41) & Yes & Yes & Yes & Yes & No & Yes & Yes & Yes & 7 \\
\hline Ye 2020 (33) & No & Yes & Yes & Yes & No & Yes & Yes & Yes & 6 \\
\hline Yang 2020 (65) & No & Yes & Yes & Yes & No & Yes & Yes & Yes & 6 \\
\hline Li 2020 (66) & Yes & Yes & Yes & Yes & No & Yes & Yes & Yes & 7 \\
\hline Cao 2020 (67) & No & Yes & Yes & Yes & No & Yes & Yes & No & 5 \\
\hline Yuan 2020 (46) & No & Yes & Yes & Yes & No & Yes & Yes & Yes & 6 \\
\hline Zeng 2020 (68) & Yes & Yes & No & Yes & No & Yes & Yes & No & 5 \\
\hline Chen 2020 (69) & No & Yes & Yes & Yes & No & Yes & Yes & Yes & 6 \\
\hline Hu 2020 (70) & No & Yes & Yes & Yes & No & Yes & Yes & No & 5 \\
\hline Zhang 2020 (71) & No & Yes & Yes & Yes & No & Yes & Yes & Yes & 6 \\
\hline Yang 2020 (72) & No & Yes & Yes & Yes & No & Yes & Yes & Yes & 6 \\
\hline An 2020 (73) & No & Yes & No & Yes & No & Yes & Yes & Yes & 5 \\
\hline Liu 2020 (74) & No & Yes & No & Yes & No & Yes & Yes & No & 4 \\
\hline Li 2020 (29) & No & Yes & Yes & Yes & No & Yes & Yes & Yes & 6 \\
\hline Shi 2020 (75) & No & Yes & Yes & Yes & No & Yes & Yes & Yes & 6 \\
\hline Lei 2020 (76) & No & Yes & Yes & Yes & No & Yes & Yes & Yes & 6 \\
\hline Sun 2020 (77) & Yes & Yes & Yes & Yes & No & Yes & Yes & Yes & 7 \\
\hline Bai 2020 (78) & No & Yes & Yes & Yes & No & Yes & Yes & No & 5 \\
\hline Chen 2020 (79) & No & Yes & Yes & Yes & No & Yes & Yes & Yes & 6 \\
\hline Zhong 2020 (80) & No & Yes & Yes & Yes & No & Yes & Yes & Yes & 6 \\
\hline Zhu 2020 (81) & No & Yes & No & Yes & No & Yes & Yes & Yes & 5 \\
\hline Li 2020 (45) & Yes & Yes & Yes & Yes & No & Yes & Yes & Yes & 7 \\
\hline Zhang 2020 (82) & No & Yes & Yes & Yes & No & Yes & Yes & No & 5 \\
\hline Zhang 2020 (83) & No & Yes & Yes & Yes & No & Yes & Yes & No & 5 \\
\hline Xia 2020 (84) & No & Yes & Yes & Yes & No & Yes & Yes & Yes & 6 \\
\hline Zheng 2020 (85) & No & Yes & Yes & Yes & No & Yes & Yes & Yes & 6 \\
\hline Sun 2020 (86) & No & Yes & Yes & Yes & No & Yes & Yes & No & 5 \\
\hline Sun 2020 (87) & Yes & Yes & Yes & Yes & No & Yes & Yes & Yes & 7 \\
\hline Xu 2020 (54) & Yes & Yes & Yes & Yes & No & Yes & Yes & Yes & 7 \\
\hline Tian 2020 (88) & No & Yes & Yes & Yes & No & Yes & Yes & No & 5 \\
\hline Chen 2020 (89) & No & Yes & Yes & Yes & No & Yes & Yes & No & 5 \\
\hline Yin 2020 (90) & No & Yes & Yes & Yes & No & Yes & Yes & No & 5 \\
\hline Yu 2020 (91) & No & Yes & Yes & Yes & No & Yes & Yes & Yes & 6 \\
\hline Cui 2020 (92) & No & Yes & Yes & Yes & No & Yes & Yes & Yes & 6 \\
\hline Shang 2020 (93) & No & Yes & Yes & Yes & No & Yes & Yes & No & 5 \\
\hline Hao 2020 (94) & Yes & No & Yes & Yes & No & Yes & Yes & Yes & 6 \\
\hline Wang 2020 (95) & No & Yes & Yes & No & No & Yes & Yes & No & 4 \\
\hline Tian 2020 (96) & No & Yes & Yes & Yes & No & Yes & Yes & Yes & 6 \\
\hline
\end{tabular}

Table S2 (continued) 


\begin{tabular}{|c|c|c|c|c|c|c|c|c|c|}
\hline Study ID & Item 1 & Item 2 & Item 3 & Item 4 & Item 5 & Item 6 & Item 7 & Item 8 & Scores $^{\dagger \dagger}$ \\
\hline Xu 2020 (37) & Yes & Yes & Yes & Yes & No & Yes & Yes & Yes & 7 \\
\hline Zhu 2020 (97) & Yes & Yes & Yes & Yes & No & Yes & Yes & Yes & 7 \\
\hline Huang 2020 (47) & Yes & Yes & Yes & Yes & No & Yes & Yes & Yes & 7 \\
\hline Jiang 2020 (48) & No & Yes & Yes & Yes & No & Yes & Yes & Yes & 6 \\
\hline Xu 2020 (54) & Yes & Yes & Yes & Yes & No & Yes & Yes & Yes & 7 \\
\hline Huang 2020 (35) & No & Yes & Yes & Yes & No & Yes & Yes & Yes & 6 \\
\hline Huang 2020 (2) & No & Yes & Yes & Yes & Yes & Yes & Yes & Yes & 7 \\
\hline Lauer 2020 (98) & No & Yes & Yes & Yes & No & Yes & Yes & Yes & 6 \\
\hline Xie 2020 (99) & Yes & Yes & Yes & Yes & No & Yes & Yes & Yes & 7 \\
\hline Shi 2020 (100) & No & Yes & Yes & Yes & No & Yes & Yes & Yes & 6 \\
\hline Deng 2020 (36) & Yes & Yes & Yes & Yes & No & Yes & Yes & Yes & 7 \\
\hline Hua 2020 (101) & No & Yes & Yes & Yes & No & Yes & Yes & Yes & 6 \\
\hline Lu 2020 (102) & No & No & Yes & Yes & No & Yes & Yes & No & 4 \\
\hline Shen 2020 (103) & No & Yes & Yes & Yes & No & Yes & Yes & Yes & 6 \\
\hline Tian 2020 (42) & Yes & Yes & Yes & Yes & No & Yes & Yes & Yes & 7 \\
\hline Shi 2020 (104) & No & Yes & Yes & Yes & No & Yes & Yes & Yes & 6 \\
\hline Hung 2020 (105) & Yes & Yes & Yes & No & No & Yes & Yes & Yes & 6 \\
\hline Zhao 2020 (106) & No & Yes & Yes & Yes & No & Yes & Yes & Yes & 6 \\
\hline Yu 2020 (107) & No & Yes & Yes & Yes & No & Yes & Yes & Yes & 6 \\
\hline Xia 2020 (108) & No & Yes & No & Yes & No & Yes & Yes & Yes & 5 \\
\hline Miao 2020 (109) & Yes & Yes & Yes & Yes & No & Yes & Yes & Yes & 7 \\
\hline Huang 2020 (49) & Yes & Yes & Yes & Yes & No & Yes & Yes & Yes & 7 \\
\hline Lam 2020 (110) & Yes & Yes & Yes & Yes & No & Yes & Yes & Yes & 7 \\
\hline Wang 2020 (111) & Yes & Yes & Yes & Yes & No & Yes & Yes & Yes & 7 \\
\hline Zeng 2020 (112) & No & Yes & Yes & Yes & No & Yes & Yes & No & 5 \\
\hline Zou 2020 (113) & No & Yes & Yes & Yes & No & Yes & Yes & Yes & 6 \\
\hline Ding 2020 (114) & No & Yes & No & Yes & No & Yes & Yes & No & 4 \\
\hline Li 2020 (115) & No & Yes & Yes & Yes & No & Yes & Yes & No & 5 \\
\hline Wu 2020 (30) & No & Yes & Yes & Yes & No & Yes & Yes & Yes & 6 \\
\hline Wang 2020 (116) & No & Yes & Yes & Yes & No & Yes & Yes & Yes & 6 \\
\hline Zhai 2020 (43) & No & Yes & Yes & Yes & No & Yes & Yes & Yes & 6 \\
\hline Tian 2020 (117) & No & Yes & Yes & Yes & No & Yes & Yes & No & 5 \\
\hline Yu 2020 (118) & No & Yes & Yes & Yes & No & Yes & Yes & No & 5 \\
\hline Tian 2020 (119) & No & Yes & Yes & Yes & No & Yes & Yes & No & 5 \\
\hline Shang 2020 (120) & No & Yes & Yes & Yes & No & Yes & Yes & Yes & 6 \\
\hline Zeng 2020 (121) & No & Yes & Yes & Yes & No & Yes & Yes & Yes & 6 \\
\hline Hong 2020 (122) & No & Yes & Yes & Yes & No & Yes & Yes & Yes & 6 \\
\hline Wang 2020 (123) & No & Yes & Yes & Yes & No & Yes & Yes & Yes & 6 \\
\hline Lin 2020 (124) & No & Yes & Yes & Yes & No & Yes & Yes & No & 5 \\
\hline Tu 2020 (125) & No & Yes & Yes & Yes & No & Yes & Yes & Yes & 6 \\
\hline Liu 2020 (126) & No & Yes & Yes & Yes & No & Yes & Yes & Yes & 6 \\
\hline Chen 2020 (127) & No & Yes & Yes & Yes & No & Yes & Yes & Yes & 6 \\
\hline Chen 2020 (128) & No & Yes & Yes & Yes & No & Yes & Yes & Yes & 6 \\
\hline Yao 2020 (129) & No & Yes & Yes & Yes & No & Yes & Yes & No & 5 \\
\hline Zhang 2020 (130) & Yes & No & Yes & Yes & No & Yes & Yes & Yes & 6 \\
\hline Duan 2020 (131) & No & Yes & Yes & Yes & No & Yes & Yes & Yes & 6 \\
\hline Leung 2020 (132) & Yes & Yes & Yes & Yes & No & Yes & Yes & Yes & 7 \\
\hline
\end{tabular}

$\mathrm{tt}^{+}$, according to the methodology evaluation tool recommended by National Institute for Health and Care Excellence. The risk of bias is evaluated according to eight criteria. The results were summarized by scoring method, for the "Yes" items, the score was 1 , and for the "no" items, the score was 0 . The maximum score is 8 ; the higher the score, the lower the risk of bias. The numbers 1 to 8 refer to the items of the tool: 1. case series collected in more than one centre, i.e., multi-centre study; 2 . is the hypothesis/aim/objective of the study clearly described? 3. are the inclusion and exclusion criteria (case definition) clearly reported? 4 . is there a clear definition of the outcomes reported? 5. were data collected prospectively? 6 . is there an explicit statement that patients were recruited consecutively? 7 . are the main findings of the study clearly described? 8. are outcomes stratified? (e.g., by disease stage, abnormal test results, patient characteristics). 


\begin{tabular}{|c|c|c|c|c|c|c|c|c|c|c|}
\hline \multirow{2}{*}{ Study ID } & \multicolumn{4}{|c|}{ Selection } & \multicolumn{2}{|c|}{ Comparability } & \multicolumn{3}{|c|}{ Exposure } & \multirow{2}{*}{ Scores $^{\dagger+}$} \\
\hline & Item 1 & Item 2 & Item 3 & Item 4 & Item 5 & Item 6 & Item 7 & Item 8 & Item 9 & \\
\hline Young 2020 (20) & * & * & * & * & * & * & * & $x$ & * & 8 \\
\hline Cummings 2020 (25) & * & $x$ & * & * & $x$ & * & * & * & $x$ & 6 \\
\hline Hu 2020 (32) & * & $x$ & * & $x$ & $x$ & * & * & $x$ & $x$ & 4 \\
\hline Liang 2020 (34) & * & * & * & * & * & * & * & $x$ & $x$ & 7 \\
\hline Qi 2020 (38) & * & * & * & $x$ & * & * & * & $x$ & $x$ & 6 \\
\hline Zhou 2020 (39) & * & * & * & $x$ & * & * & * & $x$ & $x$ & 6 \\
\hline
\end{tabular}

$\mathrm{ttt}^{\mathrm{t}}$, according to the methodology evaluation tool of Newcastle-Ottawa Scale. It consists of eight domains, for each, we will grade with stars. The more stars, the lower the risk of bias. The maximum score is 9 . A study can be awarded a maximum of one star for each numbered item within the Selection and Exposure categories. A maximum of two stars can be given for Comparability. The numbers 1 to 8 refer to the items of the tool: 1. representativeness of the exposed cohort; 2. selection of the non-exposed cohort; 3. ascertainment of exposure; 4 . demonstration that outcome of interest was not present at start of study; 5 . comparability of cohorts on the basis of the design; 6. comparability of cohorts on the basis of analysis; 7. assessment of outcome; 8. duration of follow-up; 9 . adequacy of follow up of cohorts. *, adequate; $x$, not adequate/unclear.

Table S4 Summary of findings

\begin{tabular}{|c|c|c|c|c|c|c|c|c|c|}
\hline \multirow[b]{2}{*}{ Outcomes } & \multirow{2}{*}{$\begin{array}{l}\text { No.of } \\
\text { studies }\end{array}$} & \multirow{2}{*}{$\begin{array}{l}\text { Sample } \\
\text { size }\end{array}$} & \multicolumn{5}{|c|}{ Certainty assessment } & \multirow{2}{*}{$\begin{array}{c}\mathrm{MD} \\
(95 \% \mathrm{Cl})\end{array}$} & \multirow[b]{2}{*}{ Certainty } \\
\hline & & & $\begin{array}{l}\text { Risk of } \\
\text { bias }\end{array}$ & Inconsistency & Indirectness & Imprecision & $\begin{array}{l}\text { Other } \\
\text { considerations }\end{array}$ & & \\
\hline $\begin{array}{l}\text { Duration from symptom onset to } \\
\text { first medical visit of the common } \\
\text { patients and severe patients }\end{array}$ & 6 & 1376 & Serious $^{1}$ & Not serious & Not serious & Not serious & None & $\begin{array}{l}-1.25 \\
(-1.71 \\
-0.80)\end{array}$ & $\begin{array}{l}\oplus \bigcirc \bigcirc \bigcirc \\
\text { very low }\end{array}$ \\
\hline $\begin{array}{l}\text { Duration from symptom onset } \\
\text { to admission of the common } \\
\text { patients and severe patients }\end{array}$ & 7 & 1593 & Serious $^{1}$ & Not serious & Not serious & Not serious & None & $\begin{array}{l}-1.92 \\
(-2.55 \\
-1.30)\end{array}$ & $\begin{array}{l}\oplus \bigcirc \bigcirc \bigcirc \\
\text { very low }\end{array}$ \\
\hline
\end{tabular}

${ }^{1}$, downgrade one level: the risk of bias is high due to the limitations of study design. MD, mean difference; $\mathrm{Cl}$, confidence interval.

\section{References}

58. Gao T, Xu Y, He X, et al. Epidemiological and clinical characteristics of 40 patients with coronavirus disease 2019 outside Hubei. Chinese Journal of Respiratory and Critical Care Medicine 2020;19:148-53.

59. Fu G, Deng J, Xiang J, et al. Clinical characteristics and prognosis in 51 severe cases of COVID-2019. Journal of Chongqing Medical University 2020;45:948-55.

60. Liu X, Xu Y, Hu M, et al. Epidemiological and clinical characteristics of 47 corona virus disease 2019 non-survivors in Huoshenshan Hospital. Med J Chin PLA 2020;45:475-80.

61. Huang H, Xu L, Zhang L, et al. Analysis of the Clinical Characteristics of 305 Patients with COVID-19 in Jinyintan Hospital of Wuhan City at Different Stage of the Epidemic. Herald of Medicine 2020;39:797-802.

62. Liu J, Chen C, Xia S. Clinical characteristics of 1540 patients with coronavirus disease 2019. Henan Journal of Preventive Medicine 2020;31:161-4.

63. Yu S, Cui Y, Wang Z, et al. Traditional Chinese Medicine Syndrome Analysis of Patients with Coronavirus Disease 2019 on Admission. World Chinese Medicine 2020;31:161-4.

64. Xia Y, Zou Q, Dai S, et al. Epidemiological and clinical characteristics of 33 cases of new coronavirus pneumonia in ChangSha area. Journal of Pratical Shock 2020;4:88-91.

65. Yang K, Ren M, Xiao L, et al. Epidemiological and clinical characteristics of 57 cases of new coronavirus pneumonia in nonepidemic areas. Journal of Third Military Medical University 1-5[2020-12-04].

66. Li C, Ma Q, Ying H, et al. Epidemiological features and prevention measures of COVID-19 in high incidence areas of Henan Province. Medical Journal of Wuhan University 2020;41:521-8.

67. Cao P, Li X, Yan X, et al. Retrospective epidemiological analysis of 223 patients of COVID-19 in Chongqing. Journal of Southwest University (Natural Science Edition) 2020;42:10-6.

68. Zeng X, Yu W, Sun X, et al. Analysis on COVID-19 Confirmed Patients' Activity Trajectory in Chongqing. Medicine and Jurisprudence 2020;12:43-5.

69. Chen W, Lin J, Wu S, et al. Epidemiological characteristics and infection risk factors of people with close contact with coronavirus disease 2019 patients in Fujian Province. Chin J Dis Control Prev 2020;24:562-6, 585

70. Hu S, Xu Q, Luo K, et al. Epidemiological characteristics of patients with coronavirus disease 2019 in Hunan province. Pract Prev Med 2020;27:385-8.

71. Zhang Y, Lei L, Xu Y, et al. Clinical Efficacy of Jinyinhua Oral Liquid in the Treatment of 80 Patients with Coronavirus Disease 2019. China Pharmaceuticals 2020;29:23-6.

72. Yang MW, Chen F, Zhu DJ, et al. Clinical efficacy of Matrine and Sodium Chloride Injection in treatment of 40 cases of COVID-19. Zhongguo Zhong Yao Za Zhi 2020;45:2221-31.

73. An W, Xia F, Chen M, et al. Clinical features of 11 deaths cases with COVID-19. The Journal of Practical Medicine 2020;36:1125-30.

74. Liu H, Zheng S, Chen J, et al. Analysis of EpidemioLogical Characteristics of New Coronavirus Pneumonia in Shaanxi Province and Thoughts on Prevention and Treatment of Traditional Chinese Medicine 2020;43:6-13.

75. Shi J, Ning H, Liu S, et al. Analysis of clinical and epidemiological characteristics of 65 cases of COVID-19 in Wenzhou. Journal of New Medicine 2020;51:360-4.

76. Lei $\mathrm{Y}, \mathrm{Lu} \mathrm{J}, \mathrm{Gu} J$, et al. Clinical features of 51 patients with corona virus disease 2019 in Wuhan City. Journal of Shandong University (Health sciences). 1-62020-12-04. Available online: http://kns.cnki.net/kcms/detail/37.1390.R.20200414.1315.006. html

77. Sun C, Liu P, Cui Y, et al. Comparative study on epidemiology and clinical characteristic in patients with imported and local secondary COVID-19. Journal of Chongqing Medical University 2020;45:962-7. 
78. Bai Y, Ji Z, Zhang H, et al. Analysis on the epidemiological characteristics of an outbreak of coronavirus disease 2019(COVID-19) in Xi'an. Chin J Dis Control Prev 2020;24:567-72.

79. Chen Y, Zhang T. Clinical features and CT imaging findings of patients with corona virus disease-19. CT Theory and Applications 2020;29:155-62.

80. Zhong S, Lin F, Shi L. Clinical characteristics and outcomes of the patients with COVID-19: A report of 62 cases. Med J Chin PLA 2020;45:370-4.

81. Zhu L, Guo F, Wang L. Analysis of clinical and imaging features of elderly patients with COVID-19 elderly patients. Journal of Gannan Medical University 2020;40:341-6.

82. Zhang N, Chen F, Li N. The clinical value of chest CT in the diagnosis of COVID-19. Journal of Shenyang Medical College 2020;22:206-9.

83. Zhang $\mathrm{N}, \mathrm{Xu} \mathrm{X}$, Li Y, et al. Application of chest CT in diagnosis and treatment of COVID-19 patients. Journal of Cardiovascular \& Pulmonary Diseases 2020;39:127-33.

84. Xia W, An C, Zheng C, et al. A clinical study of 34 patients of COVID-19 treated with Integrated Chinese and Western medicine. Journal of Traditional Chinese Medicine 2020;61:375-82.

85. Zheng K, Ning F, Xu Y, et al. Risk factors affecting the early treatment effect of patients with severe coronavirus disease 2019. Academic Journal of Second Military Medical University 2020;41:371-7.

86. Sun D, Zhang D, Tian R, et al. Influencing factors and clinical significance of liver function damage in patients diagnosed with COVID-19. Chin J Dig Surg 12020:360-5.

87. Sun C, Zhang XB, Dai Y, et al. Clinical analysis of 150 cases of 2019 novel coronavirus infection in Nanyang City, Henan Province. Zhonghua Jie He He Hu Xi Za Zhi 2020;43:503-8.

88. Tian K, Liu T, Yao M, et al. An event of COVI D-19 in hospital colleagues and family members. Chinese Journal of Infection Control 2020;19:696-700.

89. Chen L, Feng S, Wang F, et al. Clinical diagnosis and treatment of critical patients with novel coronavirus pneumonia. Chinese Journal of Clinical Medicine 2020;27:32-5.

90. Yin J, Li R, Wu X. Clinical characteristics of COVID-19 among hospital staff. Medical Journal of Wuhan University. doi: 10.14188/j.1671-8852.2020.0427.

91. Yu S, Cui Y, Wang Z, et al. Analysis of the relationship between clinical features and tongue manifestations of 40 cases with corona virus disease 2019. Beijing Journal of Traditional Chinese Medicine 2020;39:111-4.

92. Cui X, Li J, Mao X, et al. Clinical characteristics of Corona Virus Disease 2019 before and after treatment: a single-center retrospective study. Journal of Lanzhou University (Medical Sciences) 2020;46:55-61.

93. Shang X, Liu H, Zhu L, et al. Epidemiological and clinical characteristics coronavirus disease 2019: a report of 36 cases. Chin J Diffic and Compl Cas 2020;19:563-5, 573 .

94. Hao SR, Zhang SY, Lian JS, et al. Liver Enzyme Elevation in Coronavirus Disease 2019: A Multicenter, Retrospective, CrossSectional Study. Am J Gastroenterol 2020;115:1075-83.

95. Wang L, Duan Y, Zhang W, et al. Epidemiologic and Clinical Characteristics of 26 Cases of COVID-19 Arising from Patientto-Patient Transmission in Liaocheng, China. Clin Epidemiol 2020;12:387-91.

96. Tian S, Chang Z, Wang Y, et al. Clinical Characteristics and Reasons for Differences in Duration From Symptom Onset to Release From Quarantine Among Patients With COVID-19 in Liaocheng, China. Front Med (Lausanne) 2020;7:210.

97. Zhu W, Xie K, Lu H, et al. Initial clinical features of suspected coronavirus disease 2019 in two emergency departments outside of Hubei, China. J Med Virol 2020;92:1525-32.

98. Lauer SA, Grantz KH, Bi Q, et al. The Incubation Period of Coronavirus Disease 2019 (COVID-19) From Publicly Reported Confirmed Cases: Estimation and Application. Ann Intern Med 2020;172:577-82.

99. Xie S, Zhang G, Yu H, et al. The epidemiologic and clinical features of suspected and confirmed cases of imported 2019 novel coronavirus pneumonia in north Shanghai, China. Ann Transl Med 2020;8:637.

100. Shi X, Lu Y, Li R, et al. Evaluation of antiviral therapies for coronavirus disease 2019 pneumonia in Shanghai, China. J Med Virol 2020;92:1922-31.

101.Hua J, Chen R, Zhao L, et al. Epidemiological features and medical care-seeking process of patients with COVID-19 in Wuhan, China. ERJ Open Res 2020.

102.Lu R, Qin J, Wu Y, et al. Epidemiological and clinical characteristics of COVID-19 patients in Nantong, China. J Infect Dev Ctries 2020;14:440-6.

103. Shen Y, Zheng F, Sun D, et al. Epidemiology and clinical course of COVID-19 in Shanghai, China. Emerg Microbes Infect 2020;9:1537-45.

104. Shi S, Qin M, Shen B, et al. Association of Cardiac Injury With Mortality in Hospitalized Patients With COVID-19 in Wuhan, China. JAMA Cardiol 2020;5:802-10.

105.Hung IF, Lung KC, Tso EY, et al. Triple combination of interferon beta-1b, lopinavir-ritonavir, and ribavirin in the treatment of patients admitted to hospital with COVID-19: an open-label, randomised, phase 2 trial. Lancet 2020;395:1695-704.

106.Zhao C, Xu Y, Zhang X, et al. Public health initiatives from hospitalized patients with COVID-19, China. J Infect Public Health 2020;13:1229-36.

107.Yu T, Tian C, Chu S, et al. COVID-19 patients benefit from early antiviral treatment: A comparative, retrospective study. J Med Virol 2020;92:2675-83.

108. Xia X, Li K, Wu L, et al. Improved clinical symptoms and mortality among patients with severe or critical COVID-19 after convalescent plasma transfusion. Blood 2020;136:755-9.

109. Miao C, Jin M, Miao L, et al. Early chest computed tomography to diagnose COVID-19 from suspected patients: A multicenter retrospective study. Am J Emerg Med 2021;44:346-51.

110.Lam HY, Lam TS, Wong CH, et al. The epidemiology of COVID-19 cases and the successful containment strategy in Hong Kong-January to May 2020. Int J Infect Dis 2020;98:51-8.

111.Wang D, Yin Y, Hu C, et al. Clinical course and outcome of 107 patients infected with the novel coronavirus, SARS-CoV-2, discharged from two hospitals in Wuhan, China. Crit Care 2020;24:188.

112.Zeng M, Lei X, Hang M, et al. Epidemiological and clinical characteristics of 20 severe cases of coronavirus disease 2019 in Sichuan Province. West Chin Med J 2020;35:377-84.

113.Zou X, Yu S, Hu M, et al. Clinical characteristics of 15 hospitalized patients with critically ill coronavirus disease 2019. Journal of Internal Intensive Medicine 2020;26:116-8, 133 .

114. Ding Y, Huang Z, Zhao S, et al. Clinical and Imaging characteristics of corona virus disease 2019 (COVID-19). Radiol Practice 2020;35:281-5. 
115.Li B, Xu Y, Feng M, et al. Clinical features of COVID-19 in 40 patients. Henan J Prev Med 2020;31:404-5, 435.

116. Wang R, Xie L, Du P, et al. Clinical characteristics of 96 hospitalized patients with coronavirus disease 2019. Chinese Journal of Respiratory and Critical Care Medicine 2020;19:144-7.

117. Tian J, Dong Y, Xu C, et al. Epidemic characteristics of COVID-19 cases in Yangzhou. Prev Med 2020;32:489-91.

118. Yu C, Li X, Wang L, et al. Retrospective analysis of 608 cases of COVID-19 in outpatient and emergency department. Journal of Traditional Chinese Medicine 2020;61:1570-2

119. Tian L, Xu J, Li H, et al. Clinical characteristics of 26 cases of 2019 novel coronavirus-infected pneumonia. Journal of Nantong University (Medical Sciences) 2020;40:99-102.

120. Shang X, Liu H, Zhu L, et al. Epidemiological and clinical characteristics of patients with coronavirus disease 2019 in FuYang city, AnHui province. Chinese Journal of Difficult and Complicated Cases. 1-52020-12-05.

121.Zeng X, Xie Z, Xie Y, et al. Epidemiology of 79 confirmed COVID-19 cases and their nucleic acid test results in Changde city. Pract Prev Med 2020;27:524-6.

122.Hong Z, Zheng X, Yang X, et al. Comparative analysis of the clinical characteristics of 18 severe /critical coronavirus disease 2019 patients with myocardial injury. Chin J Arterioscler 2020;28:290-5.

123. Wang T, Hu X, Li L, et al. Analysis of Clinical Characteristics of 312 Cases of Patients with Coronavirus Disease 2019 in Fever Clinic. Herald of Medicine 2020;39:790-6.

124.Lin J, Yan K, Dai Q, et al. Retrospective study and thinking on prevention and control strategy base on COVID-19 cases in Ningbo city. Modern Practical Medicine 2020;27:524-6.

125. Tu Y, Yang P, Zhou Y, et al. Potential Predictors for Early Invasive Ventilation in Critically Ill Patients with COVID-19 in Wuhan, China: A Single-Centered, Retrospective, Observational Study. Social ence Electronic Publishing.

126.Liu J, Ouyang L, Fu P, et al. Epidemiological, Clinical, Radiological Characteristics and Outcomes of Medical Staff with COVID-19 in Wuhan, China: A Single-Centered, Retrospective Case Series Analysis. Social ence Electronic Publishing.

127. Chen X, Zhu B, Hong W, et al. Associations of clinical characteristics and treatment regimens with the duration of viral RNA shedding in patients with COVID-19. Int J Infect Dis 2020;98:252-60.

128. Chen X, Yuan W, Shao Z, et al. The Desynchrony between Clinical Course and RT-PCR Test Resultsin Patientswith COVID-19 Infected Pneumonia During the Treatment in Wuhan, China. Social Science Electronic Publishing.

129. Yao T, Gao Y, Cui Q, et al. Clinical Characteristics of 55 Cases of Deaths with COVID-19 Pneumonia in Wuhan, China: Retrospective Case Series. Social ence Electronic Publishing.

130.Zhang L, Bai T, Jin Y, et al. Diarrhea in Patients with Coronavirus Disease 2019: Clinical Characteristics, Outcomes and Implications. SSRN Electronic Journal 2020.

131.Duan Q, Guo G, Ren Y, et al. Treatment Outcomes, Influence Factors of 116 Hospitalized COVID-19 Patients with Longer/ Prolonged Treatment Course in Wuhan, China. Social ence Electronic Publishing.

132.Leung SS, Ng TL, Wu KL, et al. A Territory-Wide Study of COVID-19 Cases and Clusters with Unknown Source in Hong Kong Community: A Clinical, Epidemiological and Phylogenomic Investigation. Social ence Electronic Publishing. 